\title{
Tropical cyclone genesis potential across palaeoclimates
}

\author{
J. H. Koh and C. M. Brierley \\ Department of Geography, University College London, London, WC1E 6BT, UK \\ Correspondence to: C. M. Brierley (c.brierley@ucl.ac.uk) \\ Received: 10 December 2014 - Published in Clim. Past Discuss.: 6 February 2015 \\ Revised: 23 September 2015 - Accepted: 27 September 2015 - Published: 21 October 2015
}

\begin{abstract}
The favourability of the mid-Pliocene, Last Glacial Maximum (LGM) and mid-Holocene for tropical cyclone formation is investigated in five climate models. This is measured by a genesis potential index, derived from large-scale atmospheric properties known to be related to storm formation. The mid-Pliocene and Last Glacial Maximum (LGM) were periods where carbon dioxide levels were higher and lower than preindustrial levels respectively, while the mid-Holocene differed primarily in its orbital configuration. The cumulative global genesis potential is found to be fairly invariant across the palaeoclimates in the multi-model mean. Despite this all ensemble members agree on coherent responses in the spatial patterns of genesis potential change.

During the mid-Pliocene and LGM, changes in carbon dioxide led to sea surface temperature changes throughout the tropics, yet the potential intensity (a measure associated with maximum tropical cyclone strength) is calculated to be relatively insensitive to these changes. Changes in tropical cyclone genesis potential during the mid-Holocene are found to be asymmetric about the Equator: being reduced in the Northern Hemisphere but enhanced in the Southern Hemisphere. This is clearly driven by the altered seasonal insolation. Nonetheless, the enhanced seasonality drove localised changes in genesis potential, by altering the strength of monsoons and shifting the intertropical convergence zone. Trends in future tropical cyclone genesis potential are consistent neither between the five models studied nor with the palaeoclimate results. It is not clear why this should be the case.
\end{abstract}

\section{Introduction}

Tropical cyclones (TCs) constitute one of the most powerful forces of nature and can cause severe destruction to human life and property. How TC genesis may change in the face of climate change is thus an area of strong interest. Past studies using high-resolution general circulation models (GCMs) have generally suggested that cyclone intensity would strengthen, yet cyclone genesis would decline in a warming climate (Knutson et al., 2010). However, recent analyses of future simulations performed as part of the Coupled Model Intercomparison Project Phase 5 (CMIP5) appear equivocal: statistical downscaling indicates an increase in both cyclone intensity and genesis (Emanuel, 2013); dynamical downscaling indicates an increase in intensity combined with a reduction in frequency (Knutson et al., 2013); tracking of TC-like features in global coupled models do the same (Camargo, 2013); large-scale cyclogenesis indices have shown both frequency increases (Emanuel, 2013) and decreases (Camargo, 2013).

Understanding past climates provides a means for scientists to contextualise future climate change impacts. Palaeoclimates with altered climate forcings, such as the elevated levels of carbon dioxide during the Pliocene period, may provide clues on how the trend of cyclone genesis would respond to ongoing anthropogenic emissions of greenhouse gases.

The mid-Piacenzian warm portion of the mid-Pliocene (around 3 million years ago, henceforth "Pliocene") was a recent episode in Earth's geological history where mean global temperatures were warmer by $2-3^{\circ} \mathrm{C}$ compared to the preindustrial period (Haywood et al., 2013), but the warming was not constant across the globe. Sea surface temperature (SST) anomalies were more pronounced at the higher latitudes (up to $20^{\circ} \mathrm{C}$ in the high Arctic; Ballantyne et al., 2009), while the lower latitudes exhibited minimal change in places (Dowsett et al., 2010). The geography of the continents and oceans was relatively similar to Earth's current configuration (Haywood et al., 2011). Carbon dioxide levels were at near present-day concentrations during the mid-Pliocene (Pagani et al., 2009). There is potential of using the Pliocene to learn about the 
equilibrium state of Earth's warm climate following anthropogenic greenhouse gas influence (Haywood et al., 2009).

The icy climate of the Last Glacial Maximum (LGM) at $21 \mathrm{ka}$ serves as a contrast to the warm climates of the both Pliocene and the 20th Century. Proxy estimates by Annan and Hargreaves (2013) suggest that LGM tropical SST was around $1.6^{\circ} \mathrm{C}$ lower than preindustrial values, while global surface air temperatures were $3.1-4.7^{\circ} \mathrm{C}$ cooler. Given the relatively similar orbital parameters controlling Earth's solar insolation during the Pliocene, LGM and preindustrial periods, the focus of the Palaeoclimate Model Intercomparison Project (PMIP) on these eras helps facilitate studies that examine the effect of carbon dioxide concentration changes on the tropical climate (Table 1).

On the other hand, simulations for the mid-Holocene epoch at $6 \mathrm{ka}$ differ from preindustrial conditions mainly in the orbital parameters that result in an increased proportion of insolation reaching the high latitudes. The tropical region of the mid-Holocene period might have encountered slightly elevated SSTs of around $1^{\circ} \mathrm{C}$ (Gagan et al., 1998), although recent studies indicate some uncertainty in terms of negative SST anomaly for regions such as the western Indian Ocean (Kuhnert et al., 2014). Despite the limited proxy record agreement on whether tropical oceans may have warmed (Koutavas et al., 2002; Rimbu et al., 2004; Stott et al., 2004), prior PMIP simulations suggest SST in the Northern Hemisphere was generally warmer by less than $1{ }^{\circ} \mathrm{C}$ in the midHolocene period compared to the preindustrial era, and the Southern Hemisphere might have been slightly cooler (Braconnot et al., 2007).

Given the lack of data on tropical cyclone frequency for deep-time palaeoclimates, model simulation studies cannot seek to verify a climate model's change in cyclone formation; rather, they aim to describe tropical cyclone trends with the assumption that signals would be detectable by using indicators such as cyclogenesis potential. Using PMIP Phase 2 (PMIP2) data, studies have been conducted to investigate indices related to TC genesis activity during the LGM and mid-Holocene periods (Korty et al., 2012a, b). These have been unable to analyse simulated storms directly, due to the unavailability of 6-hourly data throughout the atmosphere in the data archive. Instead those studies (and the present one) look at indices describing how favourable the climate state is for tropical cyclogenesis. For the LGM, Korty et al. (2012a) observed higher genesis potential relative to the preindustrial era in the global mean. They also found robust regional changes, for example a shift in potential genesis from the North Atlantic to the western North Pacific (Korty et al., 2012a). For the mid-Holocene era, Korty et al. (2012b) demonstrated that the difference in distribution of the top-ofatmosphere (TOA) radiation in comparison to the preindustrial control altered the seasonal cycle of potential intensity (maximum achievable storm strength) in the Northern Hemisphere. There was a mixed response in TC genesis potential for the mid-Holocene relative to the preindustrial period: the
Northern Hemisphere becomes slightly less favourable for TC activity, whilst the Southern Hemisphere becomes more favourable.

This study aims to investigate if similar behaviours are seen in the subsequent generation of PMIP; namely the PMIP3 model ensemble. The related Pliocene ensemble (Pliocene Model Intercomparison Project - PlioMIP) is included to investigate whether there is a robust response to carbon dioxide concentrations. A further objective is to explore how factors associated with TC genesis in these palaeoclimates (equilibrium states) relate to those under future simulations (transient scenarios).

The various model simulations used in this study are described in Sect. 2. The calculation of the genesis potential index (GPI) that underpins this study will be presented in Sect. 3 of this paper along with its limitations. Section 4 consolidates the results from the GPI analysis of the various palaeoclimates derived from the GCM ensembles. Unfortunately measures of storm frequency, intensity and landfall are not possible with this methodology and so cannot be analysed. A discussion of how the climatology in the Pliocene, LGM and mid-Holocene may affect TC genesis potential relative to the preindustrial period will be covered in Sect. 5, as will the effects of elevated carbon dioxide concentration on GPI. Section 6 will summarise this paper's key findings.

\section{Climate simulations}

The PlioMIP, which complements the LGM and the midHolocene aspects of the PMIP Phase 3 (PMIP 3), coordinates the efforts of various international climate modelling teams to quantify uncertainties in model outputs using the average interglacial conditions of the mid-Piacenzian (hereafter known as Pliocene) climate boundary conditions between 3.29 and $2.97 \mathrm{Ma}$ (Haywood et al., 2011).

Nine coupled climate models participated in PlioMIP (Haywood et al., 2013), although only five are analysed here. The GCM data set selection for this study is largely dependent on data availability for the large-scale climatic variables, such as the atmospheric temperature and humidity profile, from the PlioMIP project for the Pliocene epoch. PMIP3 data for the LGM, mid-Holocene and the preindustrial period are taken from the same GCM that is used in the Pliocene simulation. In one instance, a different GCM from the same model family (MIROC) was used in the PlioMIP compared to the rest of PMIP. Here a preindustrial control from that particular GCM generation was used for comparison. A similar approach is taken for HadCM3, where intriguingly the PlioMIP and PMIP preindustrial simulations show different properties (perhaps an undocumented model improvement has been included in the PlioMIP version). Data for the representative concentration pathway $8.5 \mathrm{~W} \mathrm{~m}^{-2}$ (RCP 8.5 ) are likewise analysed as an example of a future elevated carbon dioxide 
Table 1. Trace gases and Earth's orbital parameters recommended for PMIP. The precession is specified with respect to Northern Hemispher autumnal equinox.

\begin{tabular}{lrrrrrr}
\hline Period & $\begin{array}{r}\mathrm{CO}_{2} \\
(\mathrm{ppmv})\end{array}$ & $\begin{array}{r}\mathrm{CH}_{4} \\
(\mathrm{ppbv})\end{array}$ & $\begin{array}{r}\mathrm{N}_{2} \mathrm{O} \\
(\mathrm{ppbv})\end{array}$ & Eccentricity & $\begin{array}{r}\text { Obliquity } \\
\left({ }^{\circ}\right)\end{array}$ & $\begin{array}{r}\text { Angular precession } \\
\left({ }^{\circ}\right)\end{array}$ \\
\hline Pliocene (3 Ma) & 405 & 760 & 270 & 0.016724 & 23.446 & 102.04 \\
LGM (21 ka) & 185 & 350 & 200 & 0.018994 & 22.949 & 114.42 \\
Mid-Holocene (6 ka) & 280 & 650 & 270 & 0.018682 & 24.105 & 0.87 \\
Preindustrial (control) & 280 & 760 & 270 & 0.016724 & 23.446 & 102.04 \\
\hline
\end{tabular}

concentration scenario. The GCMs that have been included in this study are outlined in Table 2.

Throughout this work, the genesis potential index presented has been calculated using monthly climatological values of the climate model variables (rather than computing a climatology of monthly varying GPI). This approach was adopted for pragmatic reasons, although Korty et al. (2012a) suggest that the impacts on the results are small. We investigated the sensitivity of this choice for a single GCM and also found it to be minor. In situations where a pre-computed monthly climatology of a particular epoch is not available on the Earth System Federation Grid, a 50-year time slice from the end of the period of interest is used to generate the monthly climatology data so as to minimise stochastic effects, model drift and internal variability. The number of vertical levels used by each model is given in Table 2. However, as the models have a hybrid vertical coordinate whilst the data in the CMIP archive is provided on constant pressure levels, the actual number of levels used for the potential intensity computation is often less. Nonetheless, all models have data from well up into the stratosphere. The GPI is only calculated between $30^{\circ} \mathrm{S}$ and $30^{\circ} \mathrm{N}$ and the cumulative values given in this study represent the integral over this latitude band. Whilst this assumes that conditions favourable for cyclogenesis only ever occur within that band, the spatial distributions seen in our results indicate that the assumption is valid. The ensemble mean is obtained by first bilinearly interpolating the individual model fields onto the coarsestresolution grid (HadCM3 in this case) and then averaging them. Any missing data (i.e. land) are infilled prior to the regridding, and then the coarsest-resolution land-sea mask is reapplied.

Calculating the range associated with internal variability in GPI is challenging. Here ten 10-year time slices are taken from a 100-year data set of the preindustrial data set of each model. The standard deviation is found to be within 1-3\% of the preindustrial TC genesis annual frequencies simulated across the five GCMs (Table 2). It is not clear to us how the longer-term internal variability (i.e. that associated with climatologies) relates to this estimate. Intuitively one may expect it to be smaller, as the climatology averages over more ENSO (El Niño-Southern Oscillation) cycles than the decadal estimates. However, research into the interannual ap- plicability of large-scale storm-related metrics (such as GPI) suggest that they underestimate the variability (Villarini and Vecchi, 2012).

\section{Genesis potential index}

The use of "genesis potential" is particularly helpful for addressing cyclone-related questions with climate models. The grid resolution of most GCMs is not sufficiently refined to simulate the mesoscale processes required to adequately capture tropical cyclones. Many studies have used genesis potential indices as a less computationally intensive and more practical approach to describe how favourable climate conditions are for tropical cyclogenesis (Bruyère et al., 2012; Camargo et al., 2007; Emanuel and Nolan, 2004; Korty et al., 2012a, b; Menkes et al., 2012; Tippett et al., 2011).

Gray (1975) pioneered work on a GPI by demonstrating the use of selected atmospheric properties to characterise climatic conditions that are favourable for cyclone genesis. Following subsequent developments (Emanuel and Nolan, 2004; Emanuel et al., 2008), the use of a GPI is considered stateof-the-art (Tippett et al., 2011). It incorporates the potential intensity theory (Emanuel, 1988; Holland, 1997) that evaluates the maximum wind speed that may be attainable using the available thermodynamic energy imparted from the atmospheric environment and the sea surface (Camargo et al., 2013) to the TC. It is worth noting that just because a genesis potential index performs well in the modern climate, it may not adequately capture the actual response of cyclogenesis to a changed climate (Camargo et al., 2014). In the following description, we must assume that the GPI described below - derived from modern observations - works as a proxy for changes in cyclogenesis in past climate simulations as well.

The GPI proposed by Emanuel and Nolan (2004) and subsequently developed by Emanuel et al. (2008) serves to synergise the thermodynamic and kinematic factors affecting TC genesis into a single index. With the aim of facilitating comparison with previous investigations into palaeoclimate cyclone genesis, the "clipped vorticity" version of the GPI employed by Korty et al. (2012a, b) has likewise been adopted 
Table 2. List of GCMs used in this study. The $b$ factor in the right column is incorporated into the GPI such that the global preindustrial value integrates to 90 annual occurrences for each GCM. HadGEM2-ES and MIROC4m are only used for the single time periods as indicated. The preindustrial simulation in PlioMIP for HadCM3 shows different behaviour to that of the PMIP simulations and so requires a different normalisation factor, $b$.

\begin{tabular}{llrrl}
\hline Model & $\begin{array}{l}\text { Atmospheric } \\
\text { resolution } \\
{ }^{\circ} \text { lat } \times{ }^{\circ} \text { long } \times \text { levels }\end{array}$ & $\begin{array}{r}b \\
\left(\times 10^{-5}\right)\end{array}$ & $\begin{array}{r}\text { Standard } \\
\text { deviation } \\
(\%)\end{array}$ & Reference \\
\hline CCSM4 & $0.9 \times 1.25 \times 26$ & 6.2 & 1.7 & Gent et al. (2011) \\
FGOALS-G2 & $2.8 \times 2.8 \times 26$ & 2.7 & 1.1 & Li et al. (2013) \\
HadCM3 & $2.5 \times 3.75 \times 19$ & $5.8(1.5)$ & 2.9 & Gordon et al. (2000) \\
(PlioMIP value) & & & & \\
HadGEM2-ES & $1.25 \times 1.875 \times 38$ & 2.7 & - & Collins et al. (2011) \\
(RCP8.5 only) & & & & \\
IPSL-CM5A & $3.75 \times 1.875 \times 39$ & 2.4 & 1.6 & Dufresne et al. (2013) \\
MIROC-ESM & $2.8 \times 2.8 \times 80$ & 1.6 & 2.5 & Sueyoshi et al. (2013) \\
MIROC4m & $2.8 \times 2.8 \times 20$ & 0.8 & - & Chan et al. (2011) \\
(Pliocene only) & & & & \\
\hline
\end{tabular}

for this study:

$$
\mathrm{GPI}=\frac{b\left[\min \left(|\eta|, 4 \times 10^{-5}\right)\right]^{3}[\max (\mathrm{PI}-35,0)]^{2}}{X_{\mathrm{m}}^{\frac{4}{3}}\left[25+V_{\text {shear }}\right]^{4}}
$$

Here, $\eta$ represents the absolute vorticity computed at the $850 \mathrm{hPa}$ level (Nolan and Rappin, 2008), $V_{\text {shear }}$ is the 200$850 \mathrm{hPa}$ wind shear value, and $\chi_{\mathrm{m}}$ is the moist entropy deficit. $\mathrm{PI}$ is the maximum potential intensity a TC can theoretically achieve (Emanuel, 1988). Due to the inherent biases in convection schemes and parameterisations employed by GCMs, the global annual total TC genesis has to be calibrated (Emanuel et al., 2008). $b$ is therefore an empirically derived normalisation factor that calibrates the GPI to achieve preindustrial cumulative annual cyclone genesis frequencies of the 90 storms observed per year in the modern period. This approach means that the percentage changes in local GPI for each model will be reflected in the ensemble mean. Previous work (Korty et al., 2012a, b) used a constant value of $b$ across the ensemble. Such an approach would mean that small absolute changes in GPI in modelled conditions biased against cyclone genesis contribute less to the ensemble mean picture. It is not clear which approach is the most relevant in this context. ${ }^{1}$

Wind shear and absolute vorticity are the two kinematic factors included in the GPI, while potential intensity and moist entropy deficit are both thermodynamic factors (Korty et al., 2012a). Wind shear, which is the vertical shear of the horizontal winds between the upper and lower troposphere, causes asymmetries in the developing cyclone which results

\footnotetext{
${ }^{1}$ In the initial submission of this manuscript the constant $b$ approach of Korty et al. (2012a, b) was used. We therefore invite the reader to compare the present figures to those visible from the openreview stage to observe the impact of this choice on the ensemble mean patterns.
}

in the ventilation of the upper-level warm core through the flushing of relatively cooler and drier air from the top (Frank and Ritchie, 2001). Stronger wind shear therefore influences inflow dynamics and weakens cyclone formation (Riemer et al., 2013). While noting caveats where such two-level vector differentials may be inadequate to describe the resultant wind shear in some scenarios (Velden and Sears, 2014), this study defines the wind shear as the difference between the 200 and $850 \mathrm{hPa}$ winds given its ease of computation.

Meanwhile, the vorticity serves as a spin-up mechanism that initiates cyclone formation in a recirculating flow that is quasi-closed in the lower troposphere. Taking the analogy of a protective pouch (Dunkerton et al., 2009), the quasi-closed streamlines surround the enhanced vorticity while nurturing the thermodynamic and convective processes that favour TC development (Tory et al., 2012). Tippett et al. (2011) observed that vorticity has a greater influence on cyclone formation at lower latitudes, and other factors play a greater role at higher latitudes. They also propose incorporating a "clipped vorticity" diagnosis in place of absolute vorticity in the GPI, so as to moderate its response in overestimating TC genesis for the subtropics. Potentially, the clipping threshold (set at $4 \times 10^{-5} \mathrm{~s}^{-1}$ in Eq. 1) may have varied in the past through large-scale changes in the atmosphere circulation. Sensitivity analysis indicates that changes in the clipping threshold have little substantive impact on the resulting change in GPI for this study (not shown).

The non-dimensional term $\left(\chi_{\mathrm{m}}\right)$ measures the moist entropy difference between the mid-troposphere and the boundary layer that is derived from asymmetric cyclone models (Emanuel, 1995b), as shown below:

$$
\mathrm{X}_{\mathrm{m}}=\frac{s_{\mathrm{b}}-s_{\mathrm{m}}}{s_{\mathrm{o}}^{*}-s_{\mathrm{b}}} \cong \frac{s^{*}-s_{\mathrm{m}}}{s_{\mathrm{o}}^{*}-s_{\mathrm{b}}} .
$$


$s_{\mathrm{m}}, s_{\mathrm{b}}$ and $s_{\mathrm{o}}^{*}$ represent the moist entropies of the midtroposphere layer, boundary layer, and the sea surface saturation entropy respectively. Taking the assumption that the lapse rate of the tropical atmosphere is largely moist adiabatic (Emanuel et al., 2008), $s^{*}$, which is the saturation entropy above the boundary layer, is assumed to be constant throughout the atmospheric column. This allows the numerator term in Eq. (2) to be evaluated at $600 \mathrm{hPa}$, which is taken to represent the mid-troposphere as defined by Emanuel (1994). $s_{\mathrm{b}}$ and $s_{\mathrm{o}}^{*}$ are calculated at $925 \mathrm{hPa}$ for the boundary layer and at the sea surface respectively. We use the Bolton (1980) equation to calculate the saturation vapour pressures needed for the Emanuel (2008) definition of moist entropy. Physically, a larger $\mathrm{X}_{\mathrm{m}}$ signifies a longer duration needed for an initial perturbation to moisten the middle troposphere before intensification occurs (Emanuel et al., 2008).

Based on the analogy of a cyclone's evolution process as equivalent to Nature's Carnot engine (Emanuel, 1988, 1991), the potential intensity diagnostic derived by Bister and Emanuel $(1998,2002)$ that takes into account the effects of dissipative heating is

Potential Intensity $(\mathrm{PI})=\sqrt{\frac{C_{\mathrm{k}}}{C_{\mathrm{d}}} \frac{\mathrm{SST}}{T_{\mathrm{o}}}\left(\mathrm{CAPE}^{*}-\mathrm{CAPE}_{\mathrm{b}}\right) .}$

$C_{\mathrm{k}}$ and $C_{\mathrm{d}}$ are the surface exchange coefficients for enthalpy and momentum. The ratio of $C_{\mathrm{k}}$ to $C_{\mathrm{d}}$ could range between 0.1 and 1.3 (Montgomery et al., 2010) and is likely between 0.75 and 1.5 for observed cyclones (Emanuel, 1995a). In this study, a ratio of $C_{\mathrm{k}} / C_{\mathrm{d}}=1$ is taken for ease of comparison with previous work that used a similar assumption (Korty et al., 2012a). $T_{\mathrm{o}}$ is an entropy-weighted mean temperature of the outflow. The convective available potential energy (CAPE*) describes an air parcel of maximum wind intensity that has been earlier saturated at the sea surface, while $\mathrm{CAPE}_{\mathrm{b}}$ describes a boundary layer air parcel which has been isothermally lowered from an equivalent air parcel of maximum wind intensity. Climate variables that are required for the potential intensity calculation are SST and sea level pressure, as well as the humidity and temperature profile of the atmospheric column. Potential intensity in this study is approximated by using a commonly applied algorithm (Bister and Emanuel, 2002). Garner (2015) provides a detailed discussion of the relationship between potential intensity and CAPE, as well as investigating the errors associated with the approximations inherent in the algorithm used here.

Having described both the genesis potential index and potential intensity, it is necessary to stress what these metrics can and, more importantly, cannot measure. Potential intensity assesses the environmental conditions and calculates the maximum strength a storm could achieve if it extracted all the available energy. It is not a measure of the actual cyclone intensity, which is often substantially smaller. The GPI is a measure of how favourable local atmospheric conditions are for tropical cyclone genesis to occur. A high GPI does not mean a storm will form at the location - other criteria such as an initial disturbance to act as storm seed are also needed. Changes in potential intensity and GPI together provide useful information about how favourable altered climates would have been for tropical cyclones to form and strengthen $(\mathrm{Ca}-$ margo et al., 2014). However, they do not give us any information about many interesting aspects of tropical cyclones, such as their distribution, tracks, size, intensity or the ocean mixing they cause.

\section{Results}

\subsection{Potential intensity}

In the tropical region, the Pliocene saw higher SSTs by about $2{ }^{\circ} \mathrm{C}$ relative to the preindustrial control (and the midHolocene), while SSTs were lower by about $2{ }^{\circ} \mathrm{C}$ at the LGM (Fig. 1). Korty et al. (2012a) suggest the $55 \mathrm{~m} \mathrm{~s}^{-1}$ potential intensity contour coincides with the region where deep convection, and hence tropical cyclogenesis, is possible. Interestingly the locations of the $55 \mathrm{~m} \mathrm{~s}^{-1}$ potential intensity contour appears to be relatively insensitive to these wholesale SST changes. For example, the contour in the North Pacific is associated with SSTs ranging from $26^{\circ} \mathrm{C}$ during the Pliocene to $22^{\circ} \mathrm{C}$ at the LGM. All climates show a rapid drop in potential intensity near $30^{\circ}$ latitude, suggesting it is valid to constrain the analysis to within this latitude band.

During the Pliocene, there is a reduction in potential intensity for the North Atlantic, despite an SST increase in the same region (Fig. 1b). This supports research showing that absolute SST by itself can be an inadequate indicator of storm strength (Vecchi et al., 2008). Whilst this may appear to depart from the early understanding of the role of threshold SST values (e.g. $26^{\circ} \mathrm{C}$ ) in influencing cyclone genesis (Palmen, 1948), it in fact underscores the importance of other factors, such as atmospheric humidity and upper troposphere outflow temperature relative to the SST, that jointly determine the magnitude of energy available to a tropical cyclone (Emanuel, 1998).

\subsection{Preindustrial period}

The preindustrial era serves as a useful reference climate as it is before Earth's environment came under substantial anthropogenic influence, especially over the tropical oceans (Lewis and Maslin, 2015). Figure 2 illustrates the GPI seen in the various GCMs in their preindustrial simulations. According to Korty et al. (2012a, b), the Northern Hemisphere shows cyclone genesis potential averaged over the peak storm periods of July, August, September and October (JASO), while the Southern Hemisphere corresponds to the peak storm period of January, February, March, April (JFMA). Monthly storm genesis will be discussed in Sect. 4.6. 


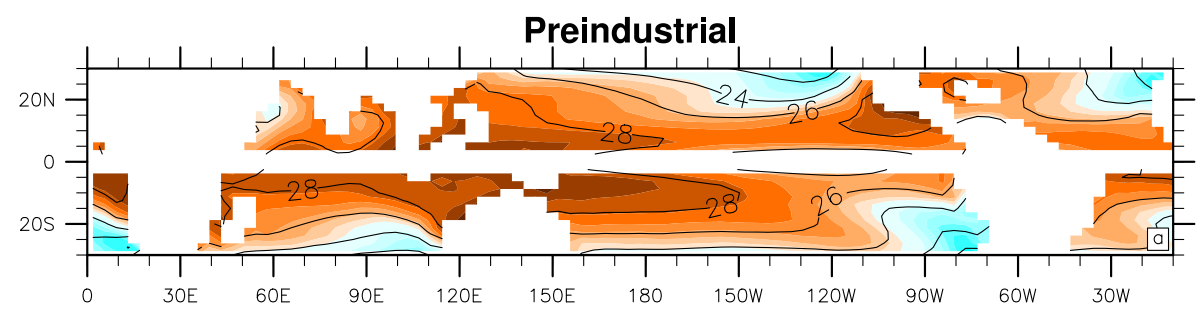

Mid-Holocene
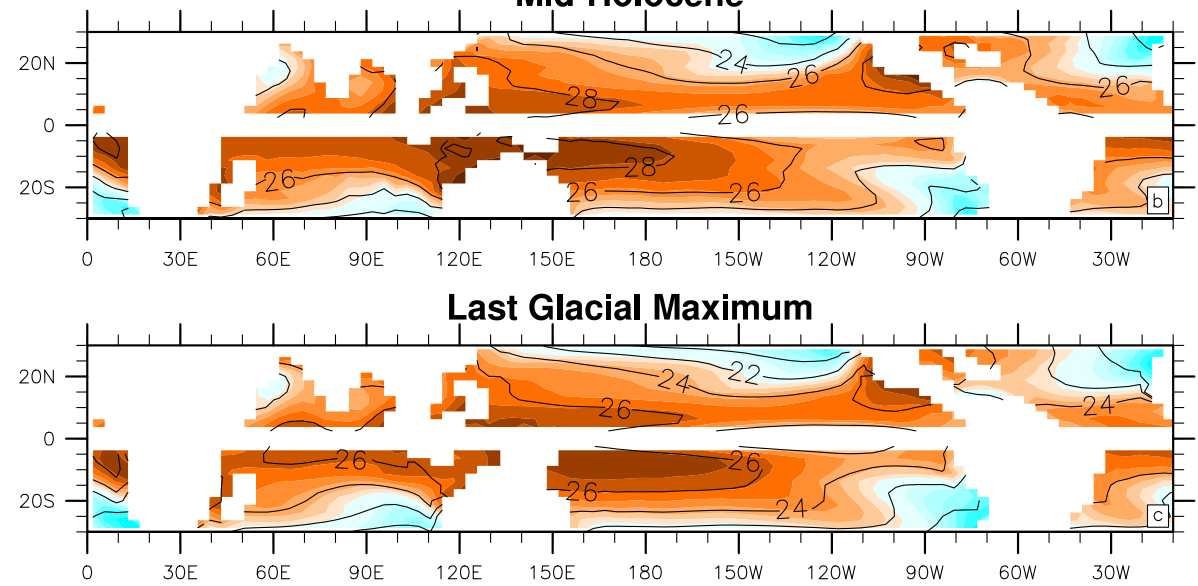

Pliocene

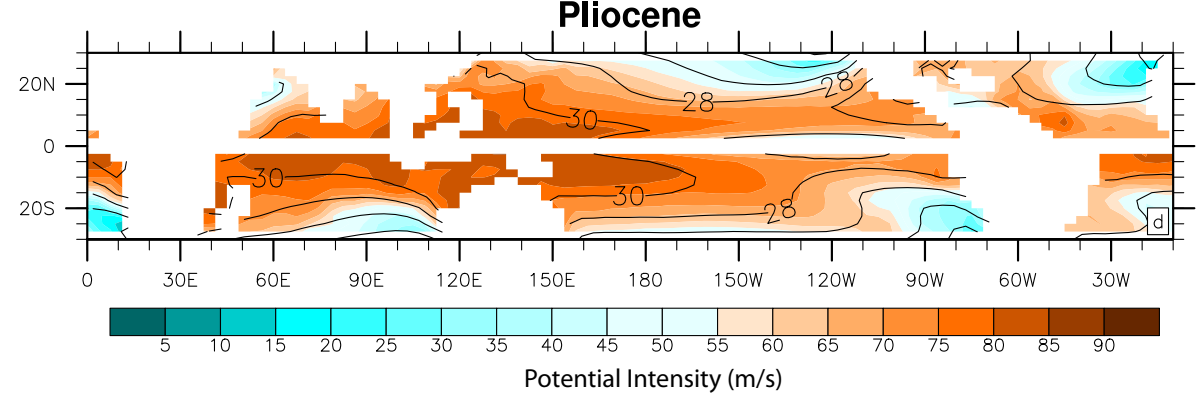

Figure 1. Sea surface temperature (contour lines) and potential intensity in the Northern Hemisphere (NH) during July-October (JASO) and Southern Hemisphere (SH) during January-April (JFMA) for (a) the preindustrial control, (b) Pliocene, (c) LGM and (d) mid-Holocene. Units are $\operatorname{SST}\left({ }^{\circ} \mathrm{C}\right)$ and potential intensity $\left(\mathrm{m} \mathrm{s}^{-1}\right)$.

The GPI distribution of the various GCMs compares favourably with the outcomes from similar model analysis by Camargo (2013) for the preindustrial period, despite the use of slightly different genesis potential indices. All models simulate conditions favourable for cyclone genesis from the eastern and western Pacific in the Northern Hemisphere during JASO, as well as the eastern Pacific near the South Pacific Convergence Zone (SPCZ) during JFMA. Stronger GPI in the southern Indian Ocean is found during JFMA, with limited genesis potential in the northern Indian Ocean during JASO apart from some areas such as the northern Bay of Bengal. The North Atlantic features some high genesis potential in the Gulf of Mexico and under the intertropical convergence zone (ITCZ), but the South Atlantic shows almost negligible potential for TC genesis. These features are all shown in observations of actual tropical cyclone genesis (Knapp et al., 2010). It should however be remembered that the genesis potential index is optimised precisely to replicate these spatial and seasonal characteristics.

However, the various models do show some biases. CCSM4 and IPSL-CM5A-LR exhibit a band of GPI in the North Pacific that is too zonal. The east-west split in HadCM3, FGOALS-G2 and MIROC-ESM is more representative of Pacific observations. However, both HadCM3 and MIROC-ESM have a west Pacific development region that is not sufficiently favourable for cyclogenesis and is constrained to the coastal regions. While IPSL-CM5ALR suggests that the central-western Pacific has the most favourable conditions for cyclone genesis, MIROC-ESM and HadCM3 show their greatest GPI in the north-eastern Pacific. FGOALS-G2 shows a relatively uniform strength of genesis potential across all the oceans, apart from an area of increased intensity in the eastern North Pacific and Philippine Sea. The genesis potential also stretches across a greater area 

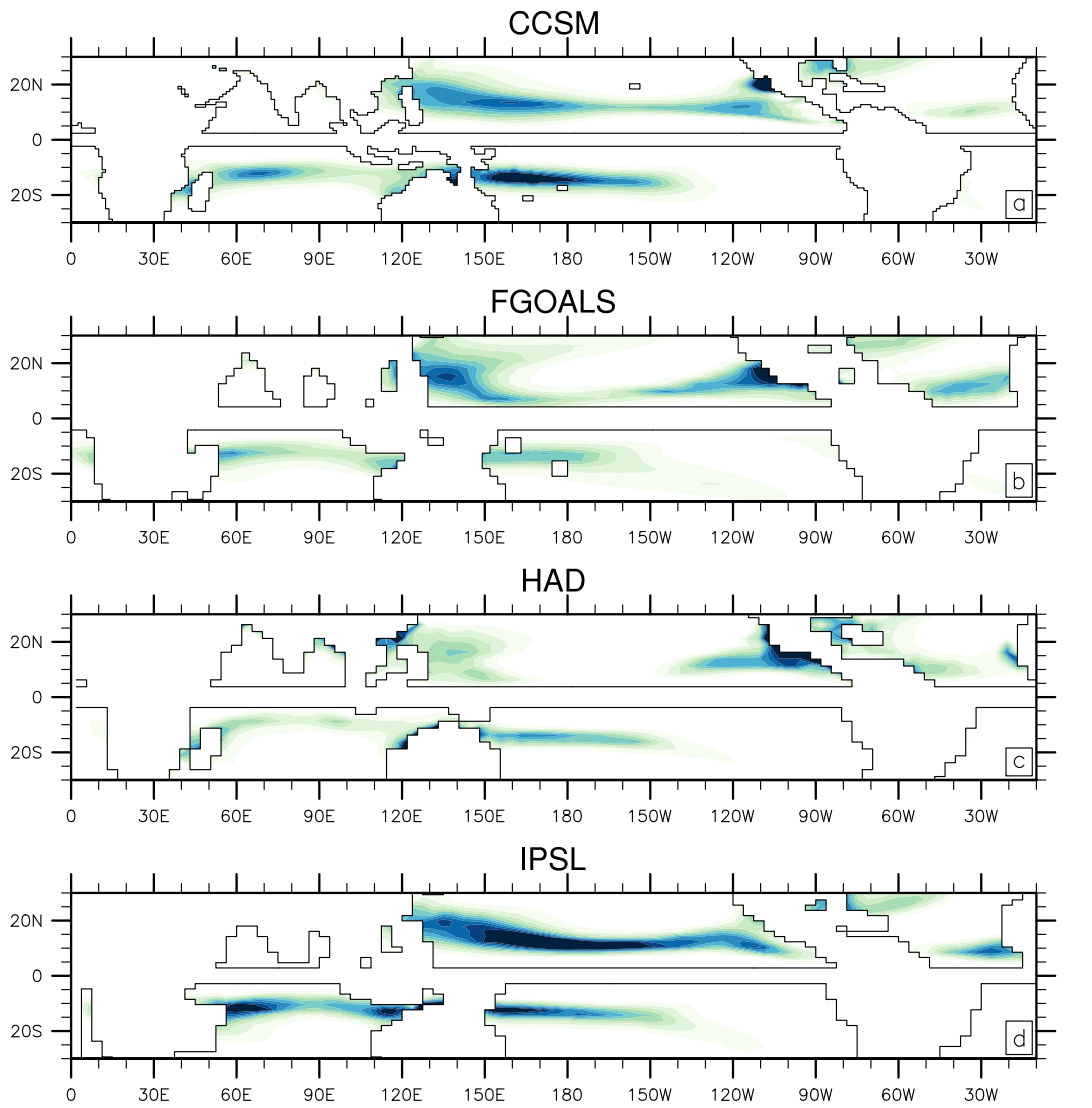

MIROC
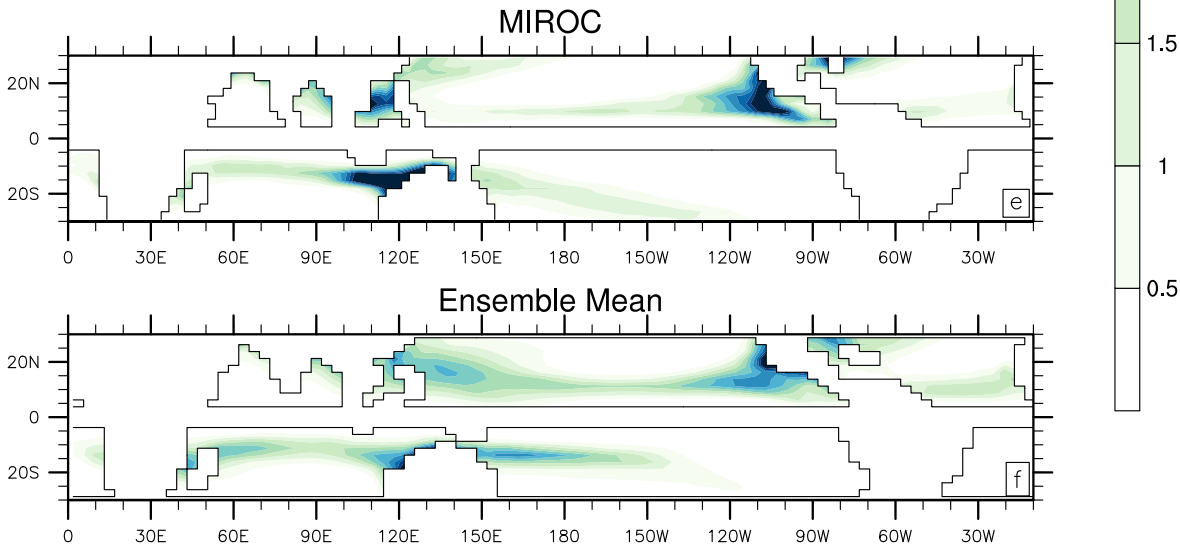

Figure 2. Preindustrial genesis potential index from (a) CCSM4, (b) FGOALS-G2, (c) HadCM3, (d) IPSL-CM5A-LR, (e) MIROC-ESM and (f) the ensemble mean. The Northern Hemisphere depicts JASO monthly mean GPI, while the Southern Hemisphere depicts JFMA monthly mean GPI. Units are $10^{-13}$ normalised occurrences $\mathrm{m}^{-2}$ month $^{-1}$.

in FGOALS-G2 relative to the other models. There appears insufficient GPI in the North Atlantic in nearly all the models, although CCSM4 and MIROC-ESM are especially weak. The Southern Hemisphere has a band of high GPI that is again a little too zonal in nature, although the southerly curvature in MIROC-ESM is considerable. This feature arises from the bias in the model representation of the SPCZ (SaintLu et al., 2015).
The ensemble mean (Fig. 2f) averages out several of the biases seen by individual models. This PMIP3 preindustrial ensemble reveals highly similar distribution of genesis potential index for regions such as the North Atlantic, Pacific and Indian oceans in comparison with the $0 \mathrm{ka}$ genesis potential from Korty et al. (2012a) calculated using PMIP2 data from seven GCMs. In both instances, the highest intensity of genesis potential is located between the $10-20^{\circ}$ latitude belts of the respective peak storm periods of both hemispheres, and 

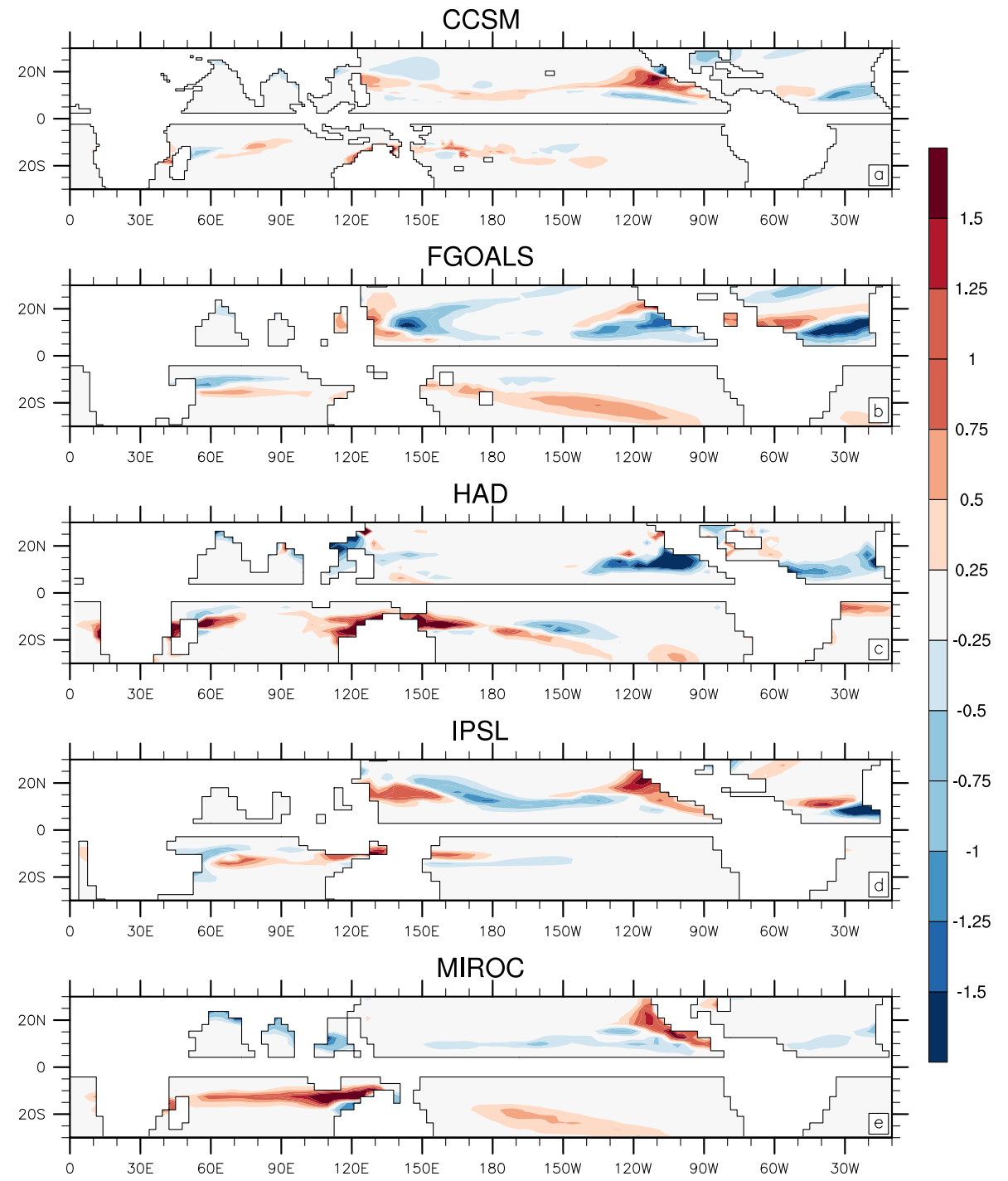

Figure 3. The difference in genesis potential index between mid-Holocene and preindustrial periods in the Northern Hemisphere (JASO) and the Southern Hemisphere (JFMA) for (a) CCSM4, (b) FGOALS, (c) HadCM3, (d) IPSL, and (e) MIROC-ESM. Units are 10-13 normalised.

both are of comparable cumulative genesis magnitude of between 3 and 5 occurrences $\mathrm{m}^{-2}$ month $^{-1}$ (not shown). The preindustrial climate thus exhibits consistency in favourable cyclogenesis locations between the PMIP3 and PMIP2 simulations (note however that HadCM3 occurs in both ensembles and all other PMIP3 models have an earlier generation entered in PMIP2).

\subsection{Mid-Holocene}

The key difference between the mid-Holocene and preindustrial climate lies in the changes in solar insolation arising from a different angular precession (Table 1). As a result, the Northern Hemisphere receives proportionally greater insolation during its storm season compared to the Southern Hemisphere. The summer and annual mean insolation for the high latitudes in both hemispheres is also increased (Braconnot et al., 2007).

These insolation changes drive responses in simulated genesis potential index across the five models (Fig. 3). The magnitude of the response in all models is similar. HadCM3 and MIROC-ESM show a widespread reduction in genesis potential in the Northern Hemisphere compensated for by an increase in the Southern Hemisphere. The response of IPSLCM5-LR and CCSM4 bear similarities to each other in that their bands of GPI in the North Pacific become more zonal (as visible in the dipole patterns in Fig. 3).

The ensemble genesis potential for the mid-Holocene (Fig. 4a) shows a largely similar distribution to the preindustrial period (Fig. 2f), although a broadly coherent pattern of GPI change is observed (Fig. 4b). The Southern Hemisphere exhibits a weak increase in GPI from the mid-Holocene to 

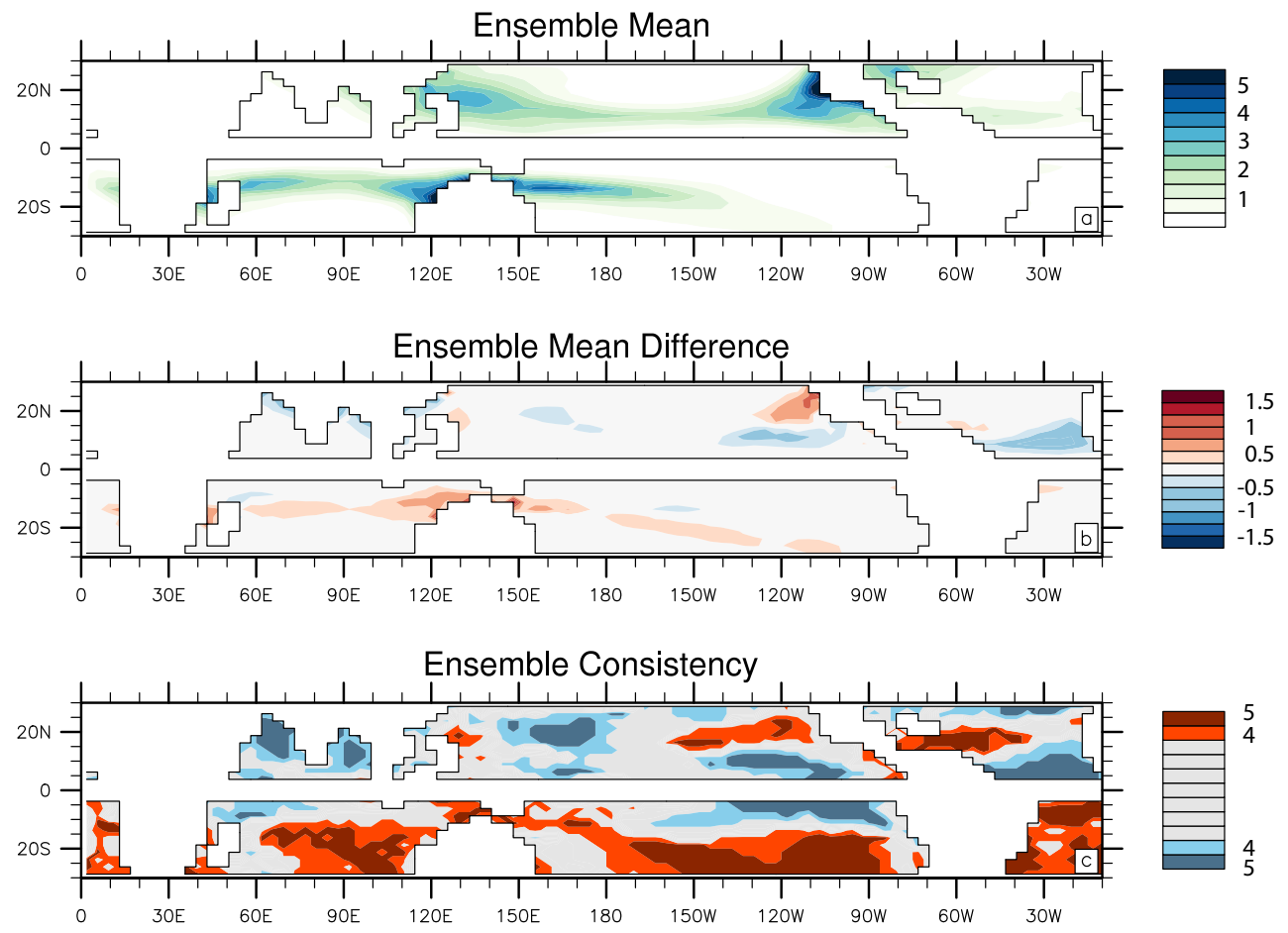

Figure 4. Panel (a): mid-Holocene ensemble genesis potential index; panel (b): mid-Holocene and preindustrial control ensemble GPI difference; and panel (c): robustness of the palaeoclimate genesis potential signals, as indicated by the number of models agreeing with the direction of the change. Yellow and red denote areas for model agreement on positive sign change. Green and blue areas denote model agreement on negative sign change. Northern Hemisphere depicts JASO season, while Southern Hemisphere depicts JFMA season. Units in (a) and (b) are $10^{-13}$ normalised occurrences $\mathrm{m}^{-2}$ month $^{-1}$.

the preindustrial period, except for pockets around northern Australia that show a stronger increase. A northward shift in GPI is noticeable in the eastern North Pacific, unsurprisingly associated with the local shift in ITCZ. This shift in the ITCZ would be expected to not only impact the genesis of storms (Merlis et al., 2013) but also their intensity (Ballinger et al., 2015). A slight decrease in genesis potential is seen in the North Atlantic.

There is a good agreement across the ensemble on the sign of the mid-Holocene change in most areas amongst the five GCMs (Fig. 4c). There is a general decrease in GPI in the Northern Hemisphere and an increase in GPI as one moves polewards in the Southern Hemisphere. Although several regions show strong agreement for increased GPI, such as the south-east Pacific and South Atlantic, these are regions of minimal cyclone occurrence at present (Knapp et al., 2010) and should not be interpreted as having storms in the midHolocene.

The results for the mid-Holocene using these PMIP3 models bear strong similarities with findings from Korty et al. (2012b) that detail cyclone genesis potential using an ensemble from ten GCMs from PMIP2. The magnitude and distribution of genesis potential changes share similar patterns across all oceans. Nonetheless this study simulates a slightly weaker genesis potential for the western south Indian Ocean and the South Atlantic, as well as a slightly weaker increase in genesis potential for the mid-Holocene to preindustrial period in both hemispheres. The model agreement (Fig. 4c) is also similar to that of Korty et al. (2012b) with both showing an anvil-shaped area of reduced GPI in the central North Pacific.

\subsection{Last Glacial Maximum (LGM)}

During the LGM, the tropics experienced cooling of $2-5^{\circ} \mathrm{C}$ over land, while most of the tropical surface ocean did not encounter cooling beyond $2{ }^{\circ} \mathrm{C}$ especially in the Southern Hemisphere (Waelbrook et al., 2009). The LGM mean tropical SST from the five GCMs in this study during the peak storm period is $2.0^{\circ} \mathrm{C}$ cooler than preindustrial temperatures. Simulated genesis potential responses for the LGM show variations both spatially and across the ensemble (Fig. 5). CCSM, HadCM3 and MIROC show generally stronger potential genesis, while FGOALS and IPSL show a weakening in genesis potential relative to the preindustrial period. All of the models show some form of compensation, indicative of shifts in the relative dominance of the TC formation locales.

The ensemble genesis potential for the LGM (Fig. 6a) shares again, at first glance, a similar distribution with the preindustrial period. However, it exhibits greater intensity 

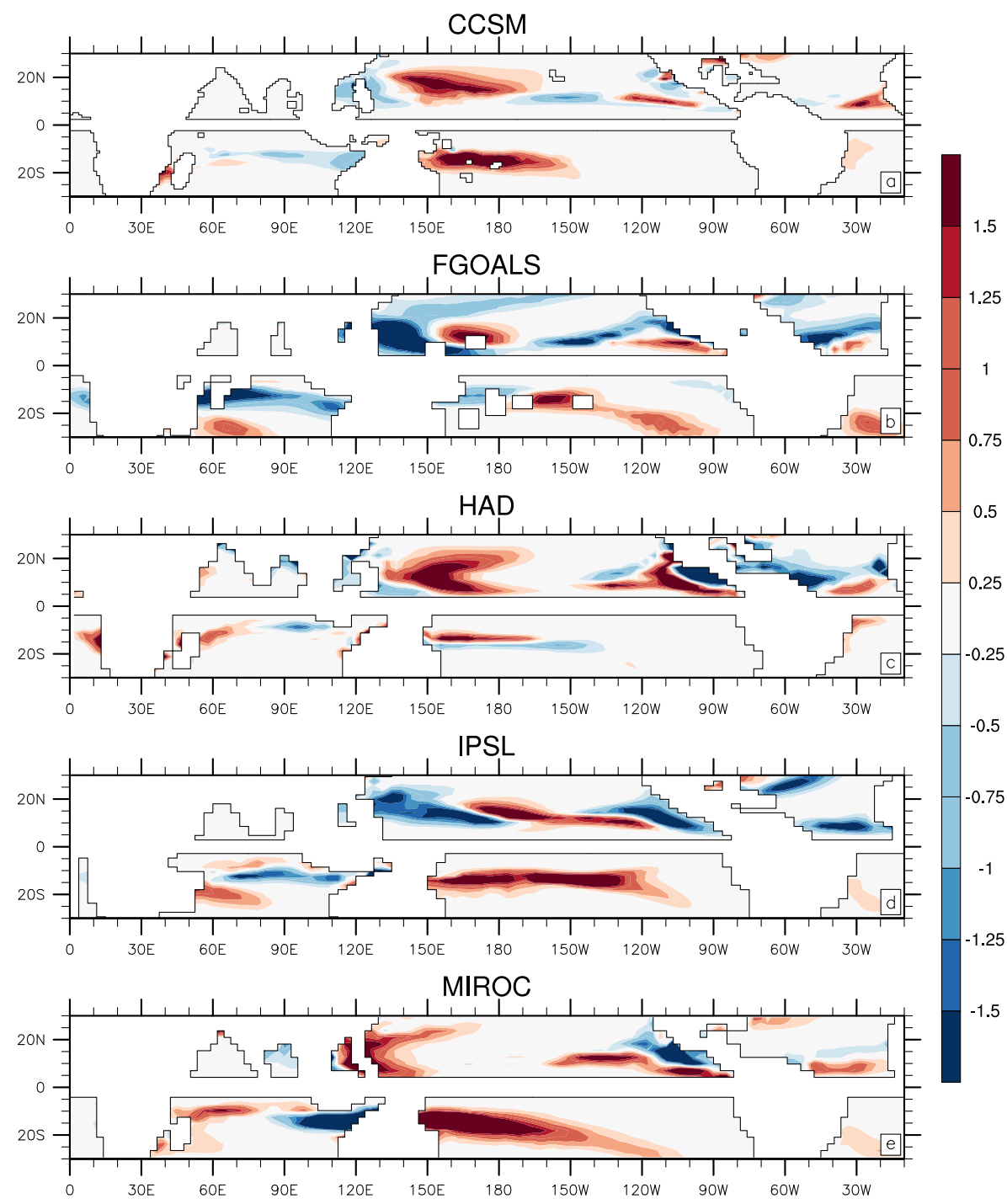

Figure 5. The difference in genesis potential index between LGM and preindustrial period in the Northern Hemisphere (JASO) and the Southern Hemisphere (JFMA) for (a) CCSM4, (b) FGOALS, (c) HadCM3, (d) IPSL, and (e) MIROC-ESM. Units are $10^{-13}$ normalised occurrences $\mathrm{m}^{-2}$ month $^{-1}$.

of genesis potential in the central North Pacific and near the SPCZ (Fig. 6b). The central-eastern south Indian Ocean shows a decrease in genesis potential along $10^{\circ} \mathrm{S}$, whilst the South Pacific sees an increase. Some of this shift in GPI is related the increased land exposure in the Maritime continent at the LGM - a feature that is treated somewhat differently between the models (observe the land masks in Fig. 5). There are slight decreases of genesis potential observed in the North Atlantic.

There is some model agreement (Fig. 6c) focussed around the largest changes in genesis potential in the LGM period for most oceans relative to the preindustrial period. The North Atlantic exhibits a very robust decrease in genesis potential that spreads over Central America into the eastern North Pacific. This is likely a response to the imposition of the Lau- rentide ice sheet and its impact on the regional circulation. There appears to be a dipole pattern in the Indian Ocean (most noticeable in Fig. 6c), although it is not as robust. This is likely an expression of the alteration in the Walker Circulation (DiNezio et al., 2011), whose fidelity varies across models depending on their parameterisations and boundary conditions (DiNezio and Tierney, 2013). These patterns of the model agreement are qualitatively similar to those seen in the PMIP2 experiments (Korty et al., 2012a) yet show more consistency across the ensemble.

\subsection{Pliocene}

The Pliocene is a warmer climate compared to the preindustrial period (Dowsett et al., 2010; Haywood et al., 2013), with 

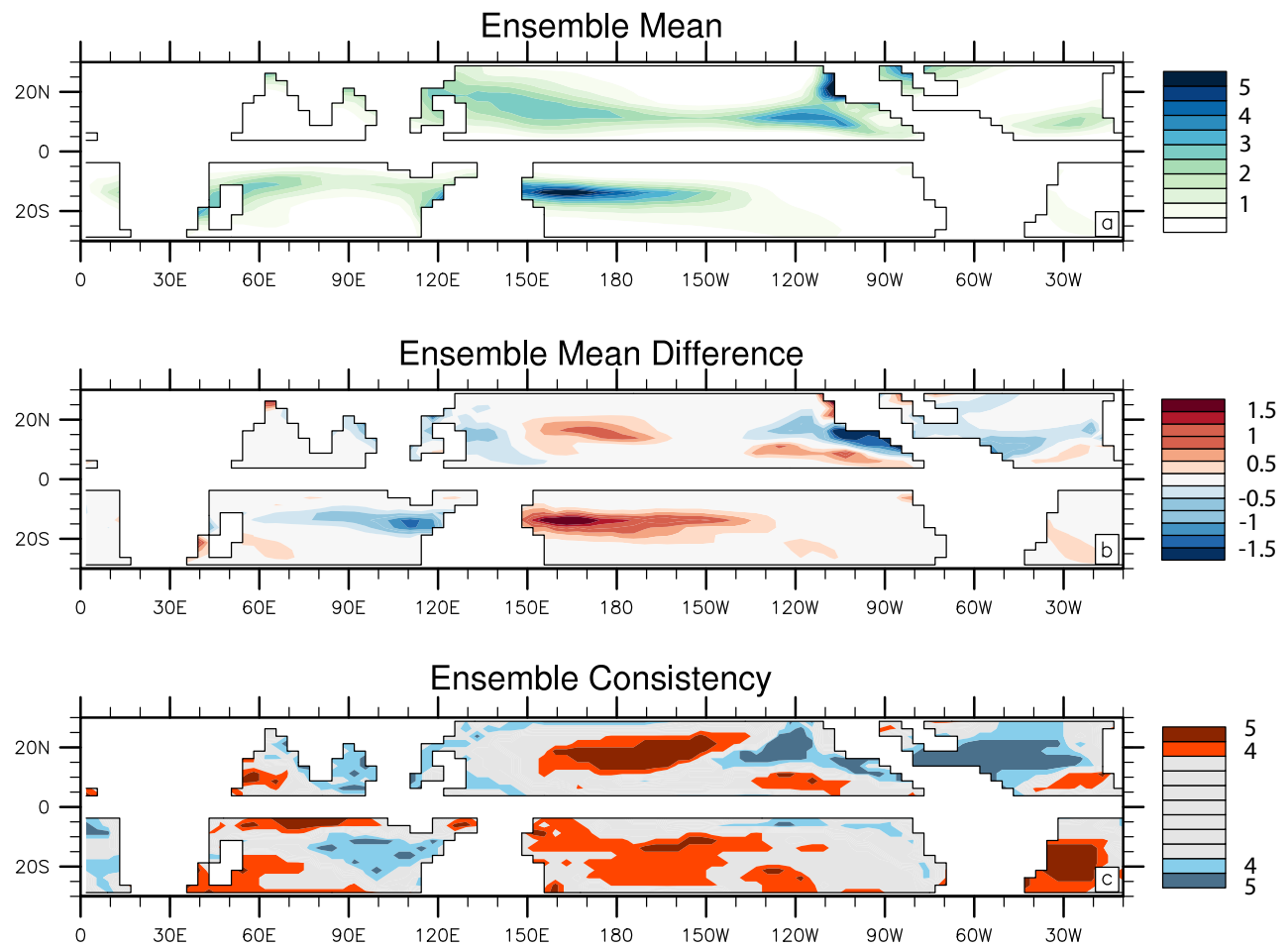

Figure 6. Panel (a): LGM ensemble genesis potential index: panel (b): LGM and preindustrial ensemble genesis potential index difference; and panel (c): robustness of the ensemble signals, as indicated by the number of models agreeing with the direction of the change. Yellow and red denote areas for model agreement on positive sign change. Green and blue areas denote model agreement on negative sign change. White areas denote regions where less than four models agree. The Northern Hemisphere depicts JASO season, while the Southern Hemisphere depicts JFMA season. Units in (a) and (b) are $10^{-13}$ normalised occurrences $\mathrm{m}^{-2}$ month $^{-1}$.

the area-averaged tropical SST from the five GCMs in this study over the peak storm season being $1.7^{\circ} \mathrm{C}$ warmer. In terms of the GPI difference from preindustrial values (Fig. 7), most models suggest a mixed response in the direction of change for various oceans, apart from MIROC4m, which shows only a limited change. The majority of models indicates a decrease in genesis potential for the North Atlantic and south Indian oceans. In the North Pacific Ocean, the majority of models suggests a decrease in genesis potential in the eastern development region, but appear to have mixed responses for the western region and the SPCZ.

As for the preindustrial period, the conditions most favourable to cyclone genesis in the Pliocene ensemble mean can be found in the eastern and western areas of the North Pacific, the SPCZ and central region of the South Pacific, as well as the north-western corner of the south Indian Ocean (Fig. 8a). In terms of the difference in genesis potential between the Pliocene and preindustrial periods (Fig. 8b), the North Atlantic, North Pacific, and south Indian oceans and the SPCZ region experience a decline in favourable cyclogenesis conditions. It is worth noting that HadCM3 simulates a reduction in GPI for nearly all regions of observed cyclogenesis (Fig. 7c).
This large-scale pattern appears to be robust as most models suggest a general decrease in genesis potential for the Pliocene relative to the preindustrial period for most oceans (Fig. 8c), although the magnitude of change might be small in areas such as the South Atlantic and eastern South Pacific. There appears to be weaker model agreement on the sign of change for the subtropical latitudes for the Pacific and Indian oceans in both hemispheres, although a slight increase in genesis potential may be expected.

\subsection{Genesis frequency}

Figure 9 illustrates the cumulative annual global genesis potential index generated from the five GCMs across the various palaeoclimates as a percentage of the preindustrial values. Remember each preindustrial GPI field is normalised such that this sum equals 90 - roughly akin to the observed number of storms formed globally each year in the modern climate. The ensemble-mean annual global totals for the Pliocene, LGM and mid-Holocene are determined to be 89 , 97 and $101 \%$ of the preindustrial values respectively.

Estimating the natural variability (or more strictly "internal variability") of an ensemble mean number is problematic. As a pragmatic measure, we take that of the model with 

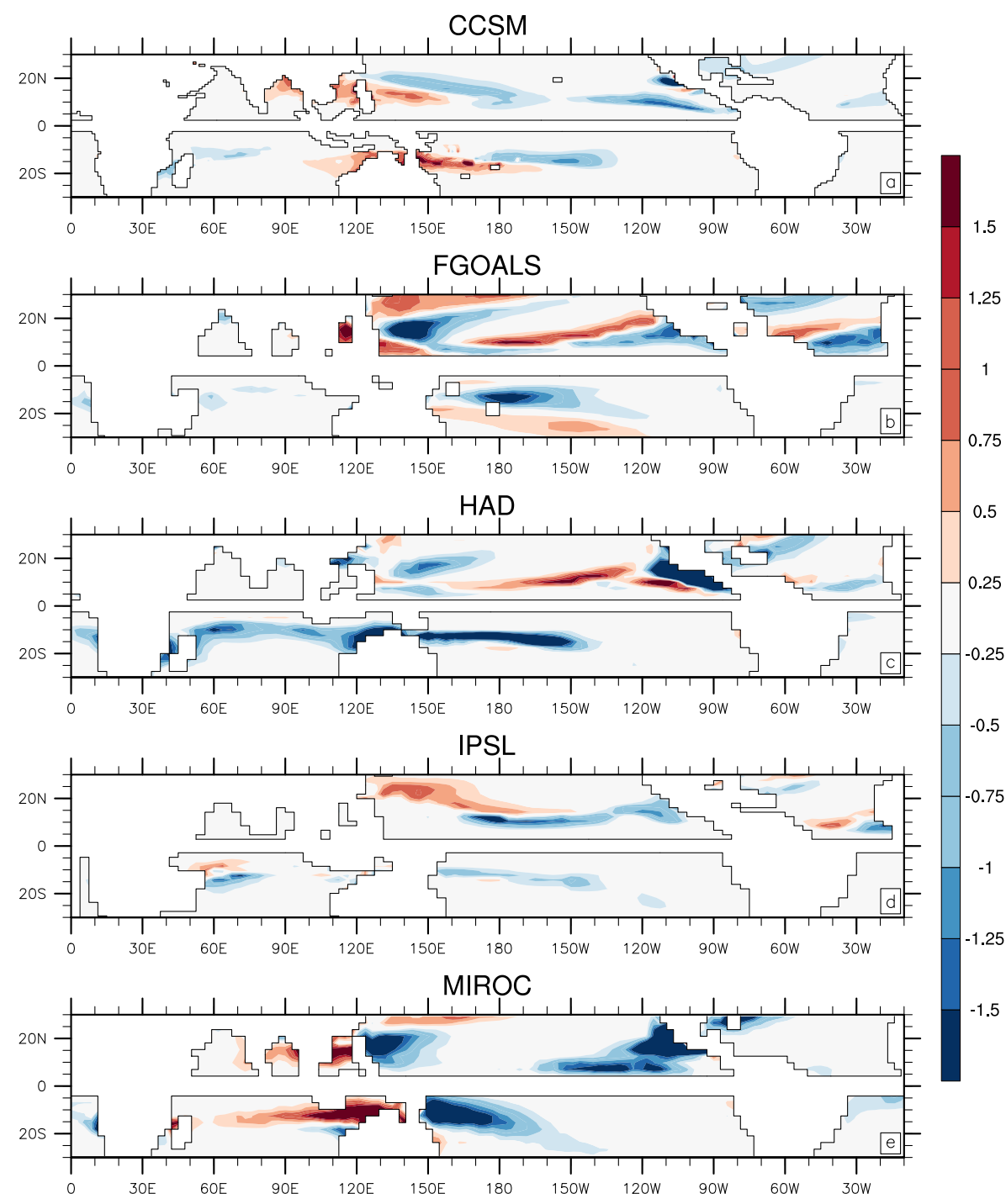

Figure 7. Change in genesis potential index between the Pliocene and the preindustrial period in the Northern Hemisphere (JASO) and the Southern Hemisphere (JFMA) for (a) CCSM4, (b) FGOALS, (c) HadCM3, (d) IPSL, and (e) MIROC4m. Units are in $10^{-13}$ normalised occurrences $\mathrm{m}^{-2}$ month $^{-1}$.

the highest internal decadal variability (HadCM3) - giving a standard deviation $(\sigma)$ of $2.9 \%$. Given that the ensemble cumulative values are generally within the standard measure of $2 \sigma$ (Haywood et al., 2013), the cumulative GPI for both the LGM and mid-Holocene is considered to have not deviated significantly from the preindustrial era. Whilst the ensemble mean value for the Pliocene is statistically significant by this metric, the magnitude of the reduction is in fact driven primarily by the HadCM3 member (the ensemble average without it is $98 \%$ of the preindustrial value). The assumption of a Gaussian distribution inherent in this metric of significance is clearly not valid for this ensemble. It is therefore not clear whether we can consider the reduction seen in the Pliocene ensemble as robust feature. This is especially true in light of the uncertainty in the internal variability measure itself, dis- cussed in Sect. 2.2. Despite this note of caution, it is worth remembering that these GPI changes are of a similar magnitude to those seen in projections of the future(Camargo, 2013; Emanuel, 2013), which are anticipated to have societal consequences.

In Fig. 10, the Northern Hemisphere peak in JASO appears consistent across the various epochs, as does the Southern Hemisphere's peak in JFMA. This justifies the choice of the peak storm seasons for the respective hemisphere as presented here. Previous work by Korty et al. (2012a, b) using PMIP2 data showed a stronger peak for the Southern Hemisphere relative to the north, while this study suggests a stronger Northern Hemisphere peak. This suggests that the PMIP3 simulations may have improved accuracy in describing present-day trends of the Northern Hemisphere for 

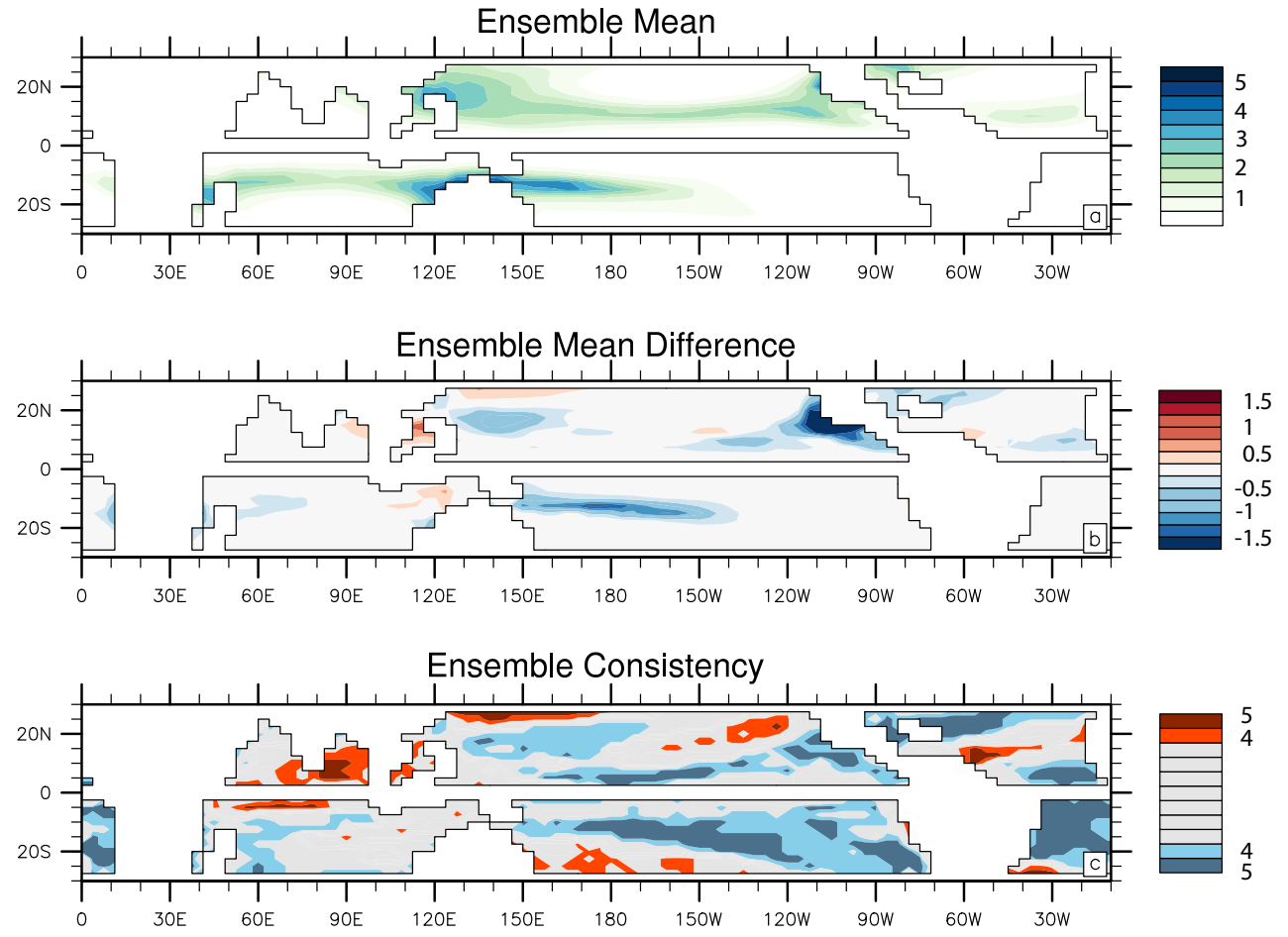

Figure 8. Panel (a): pliocene ensemble GPI; panel (b): Pliocene and preindustrial ensemble GPI difference; and panel (c): robustness of the ensemble signals, as indicated by the number of models agreeing with the direction of the change. Yellow and red denote areas for model agreement on positive sign change. Green and blue areas denote model agreement on negative sign change. White areas denote regions where less than four models agree. The Northern Hemisphere depicts JASO season, while the Southern Hemisphere depicts JFMA season. Units in (a) and (b) are $10^{-13}$ normalised occurrences $\mathrm{m}^{-2}$ month $^{-1}$.

conditions more conducive to cyclone genesis (Gray, 1968; Klotzbach, 2006; Webster et al., 2005).

Korty et al. (2012a) found a slight increase in cumulative GPI at the LGM in the previous generations of models. This ensemble shows a marginal reduction in this metric, yet there is substantial spread between the models themselves (Fig. 9). The reduced TC genesis potential index associated with the warm Pliocene conforms to the Knutson et al. (2010) view of future behaviour. It differs from the sole prior Pliocene TC study (Fedorov et al., 2010), both in results and approach. A comparison of the two pieces of work follows in Sect. 5.1.

For the mid-Holocene epoch, a salient increase in October activity is observed by Korty et al. (2012b), which has been attributed to a delayed SST response from the TOA insolation forcing, resulting in a shift of the Northern Hemisphere storm season. However, such a feature is not observed in this study. Annual SST changes are found to have varied minimally relative to the preindustrial temperatures (Fig. 1), suggesting that the ocean component during the mid-Holocene may play a lesser role in comparison to the Pliocene and LGM epochs, where more substantial SST changes are observed.

\section{Discussion}

During the Pliocene and LGM, changes in carbon dioxide led to sea surface temperature (SST) changes throughout the tropics, yet the potential intensity of TCs is observed to be relatively insensitive to these changes (Fig. 1). The annual global cumulative genesis potential index (cumulative GPI; taken as a proxy for global storm numbers per year) is likewise found to be fairly constant across the various palaeoclimates. Despite disagreement about the changes in cumulative GPI (Fig. 9), there is some model consensus on the spatial patterns of GPI change. These changes may be attributable to changes in large-scale atmospheric properties such as carbon dioxide levels, altered topography and orbital forcing.

The key difference in forcing between the mid-Holocene and the preindustrial period lies in the orbital parameters (Table 1). Solar insolation received in the Northern Hemisphere is enhanced relative to the Southern Hemisphere as a result of the altered precession (Braconnot et al., 2007). There is a slight tropospheric warming in the Northern Hemisphere for the middle and high latitudes as a consequence of this, while general tropospheric cooling is found in the tropical region and the Southern Hemisphere. Increased genesis potential is observed during the mid-Holocene in the Southern Hemisphere, along with a slight reduction in the Northern 


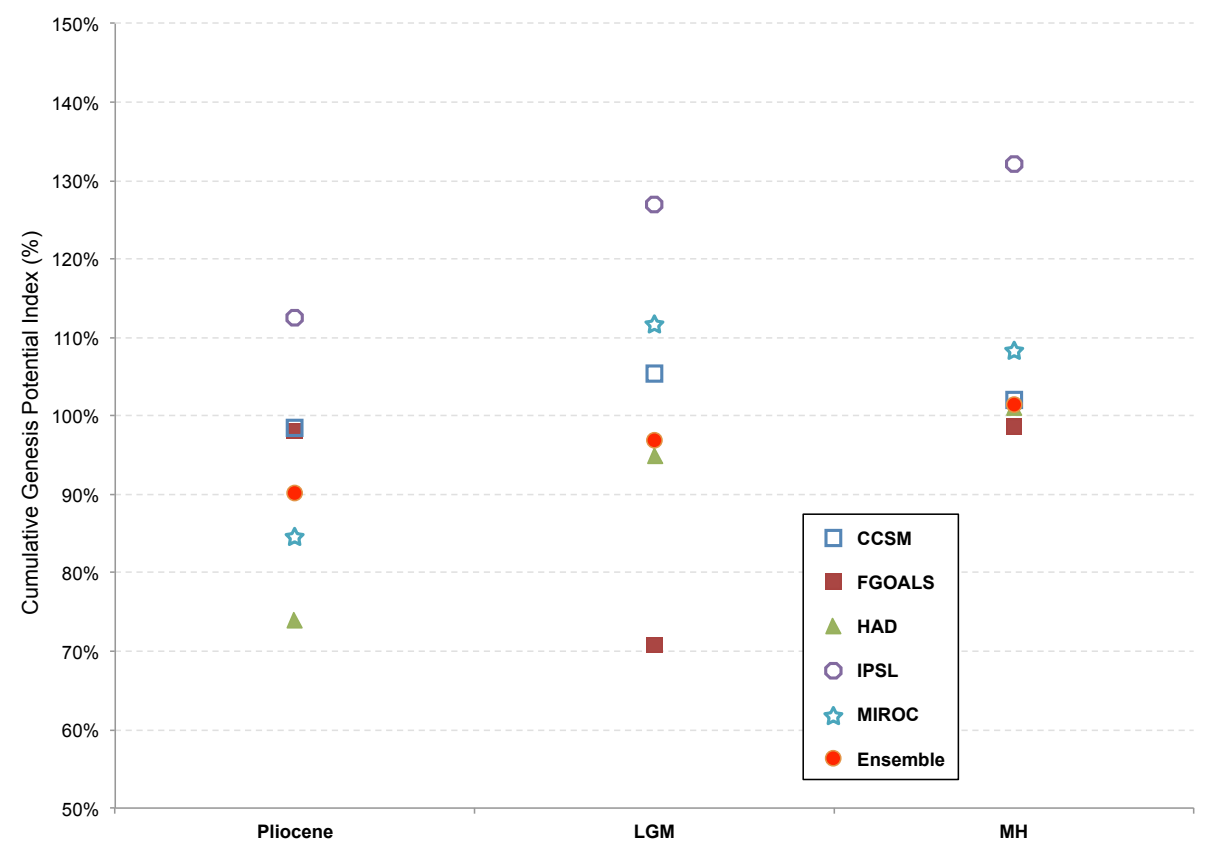

Figure 9. Model and ensemble mean cumulative annual global genesis potential index as percentage of preindustrial value.

Hemisphere (Fig. 4c). This is associated with a higher entropy deficit in the Northern Hemisphere (not shown) which would act to hinder cyclone genesis compared to the Southern Hemisphere as found by Korty et al. (2012b). The potential intensity increases very slightly at all latitudes (not shown).

Carbon dioxide, being a well-mixed greenhouse gas, causes globally coherent temperature changes in contrast to orbital forcing. The Pliocene represents a period of elevated carbon dioxide concentration resulting in a warmer climate relative to the preindustrial period, while the LGM era experienced an opposite cooling effect arising from lower carbon dioxide levels present at that time. Korty et al. (2012a) emphasise the fact that conditions at the LGM remain roughly as favourable as in the preindustrial period for tropical cyclones. They discuss the slight increase in favourably brought about local changes in the entropy deficit and wind shear terms in PMIP2. The most robust changes in GPI in the present ensemble occur in the Atlantic and appear stronger than that found by Korty et al. (2012a). The ultimate cause of this difference is likely the inclusion of altered ice sheets in the PMIP3 vs. PMIP2 experiments (Abe-Ouchi et al., 2015). This results in a small cooling of SSTs $\left(>0.5^{\circ} \mathrm{C}\right)$ stretching from the Caribbean to West Africa and consequently a change in potential intensity that is less than seen by Korty et al. (2012a).

In response to the greenhouse-gas-driven warming seen in the Pliocene experiments (Hill et al., 2014), a general decrease is observed in genesis potential in the convergence zones in both the Northern and Southern Hemispheres (Fig. 7, 8b). The PlioMIP simulations have a weaker Hadley and Walker circulation, which results in a broadening of the ITCZ (Contoux et al., 2012). Kamae et al. (2011) show that equatorial-specific humidity increases in the lower troposphere and decreases in the mid-troposphere, arising from a weakened ascent of the Walker circulation in the PlioMIP simulations. Convective processes are curtailed, leading to an associated increase in moist entropy deficit (not shown), which leads to the general decrease in GPI within the Pliocene simulations.

\subsection{Possible sea surface temperature biases and missing feedbacks}

Prior work looking at tropical cyclones in the Pliocene (Fedorov et al., 2010) shows a rather different behaviour than that found here. The two studies approach the Pliocene climate and its tropical cyclones from alternate standpoints. By summarising both approaches, we hope here to allow readers to consider their respective merits.

Fedorov et al. (2010) start with proxy SST observations from the early Pliocene $(\sim 4 \mathrm{Ma})$, which imply much weaker tropical SST gradients both meridionally (Brierley et al., 2009) and zonally (Wara et al., 2009). Although there has been some criticism of the palaeothermometers (O'Brien et al., 2014; Zhang et al., 2014a), this does not affect the estimates of reduced SST gradients (Ravelo et al., 2015; Brierley et al., 2015; although note the response of Zhang et al., 2014b). Coupled climate models seem unable to replicate this climate state (Fedorov et al., 2013). Fedorov et al. (2010) use an atmosphere-only model driven by a prescribed "Pliocene" SST field (Brierley et al., 2009) to cre- 

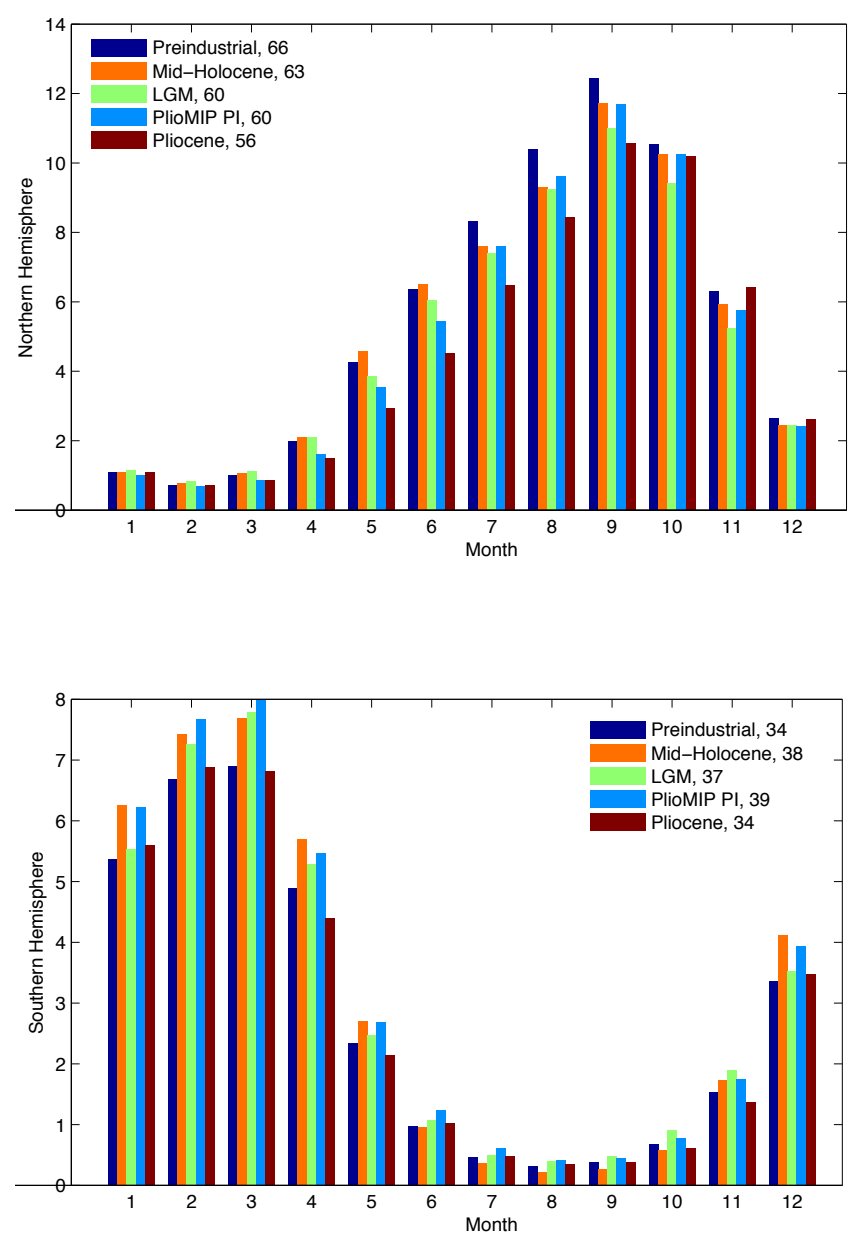

Figure 10. Ensemble monthly cumulative genesis potential index for the different time periods over (a) the Northern Hemisphere and (b) the Southern Hemisphere.

ate inputs for a statistical dynamical downscaling model (Emanuel et al., 2008). The statistics of the tropical cyclones directly simulated by the downscaling model were analysed and show a substantial increase in tropical cyclones across the globe. Fedorov et al. (2010) then focus on the increase in the central Pacific and suggest that these storms could be part of a feedback that maintains the weak zonal SST gradient on the Equator.

This study uses simulations from the PlioMIP experiment, which aims to investigate systematic biases between the palaeobservations and modelled climates of the Pliocene (Haywood et al., 2011). The PlioMIP multi-model experiment focuses on $\sim 3 \mathrm{Ma}$ and finds many similarities on the global scale (Haywood et al., 2013). There are some regions with substantial mismatch across the ensemble however, most notably the high-latitude North Atlantic and tropical Pacific. As a whole this ensemble does not show any change in the zonal SST gradient, something true of every model in the subset used here (Brierley, 2015). Aside from the limitation of using a genesis potential index, the present study may therefore include a systematic bias in its representation of the Pliocene - although it has been suggested (O'Brien et al., 2014; Zhang et al., 2014a) that in fact the palaeobservations are in error. Nonetheless it is interesting that the present study shows an increase in genesis potential in the central Pacific - impinging on the subduction zone critical for the cyclone-climate feedback discussed by Fedorov et al. (2010). Should cyclone-climate feedbacks be an important feature of the actual Earth System, then systematic biases would exist across all the simulations presented here, not only the Pliocene ones.

\subsection{Relationship to projections of the future}

Records do not currently exist to either confirm or refute the potential of the atmospheric conditions simulated by this ensemble for tropical cyclogenesis. They probably never will. Yet the Earth will shortly experience carbon dioxide concentrations beyond those of the Pliocene period. Therefore, it is interesting to consider how the results above correspond to projections of the future. One further motivation to do this is that the palaeoclimate simulations are all equilibrium experiments, whilst the projections of the future are transient. It is therefore anticipated that the climate change signal will be easier to detect in the palaeoclimate simulations. In transient simulations, large-scale forcings may not fully account for the observed variability (Menkes et al., 2012) as stochastic effects may potentially account for up to half of the observed variability (Jourdain et al., 2010).

The RCP8.5 scenario is used to project how GPI may develop in future. It is chosen as it is the most extreme scenario and so should have the biggest signal. In this scenario, carbon dioxide concentrations reach over $900 \mathrm{ppmv}$ by 2100 (Collins et al., 2013); more than double the level in the Pliocene simulations.

The GCMs selected in this study all show future changes in tropical cyclone count (at least as estimated by the cumulative GPI) under the RCP8.5 transient scenario (Fig. 11). Yet these trends are not consistent between the models. Note that HadCM3 has not contributed results for RCP8.5, so a later generation of the model (HadGEM2) has been substituted. Two models suggest an increase in cumulative GPI, while three models suggest a decrease, resulting in an ensemble mean with a trend of slightly reduced cumulative GPI by 2095. The future response is also seemingly inconsistent with the palaeoclimate responses in the same GCM. For example, MIROC-ESM an increased cumulative GPI under both LGM conditions and RCP8.5, despite both having opposite $\mathrm{CO}_{2}$ changes. Efforts to detect obvious relationships across the ensemble - for example between northern hemispheric temperatures and cumulative GPI - were unsuccessful (not shown).

Interestingly, the multi-model mean GPI difference between the future RCP8.5 (2071-2100) scenario and historical (1971-2000) simulation from Camargo (2013) shows 


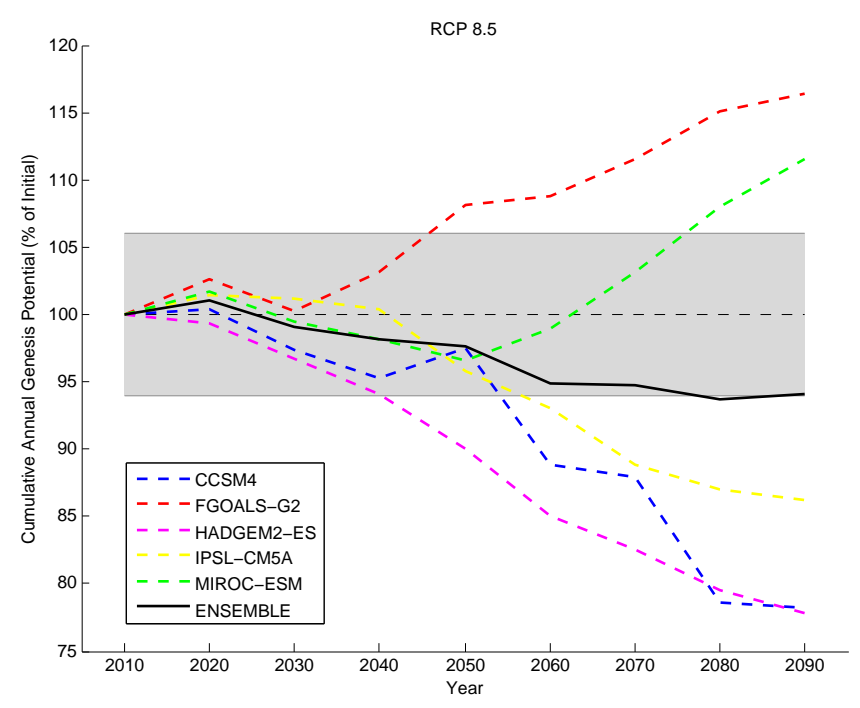

Figure 11. Cumulative annual global cyclone genesis potential index simulated under the RCP8.5 scenario between 2005 and 2095. The shaded area represents the spread expected from internal variability alone, from the baseline of 90 cumulative occurrences observed in modern day (black dashed line).

an opposite pattern to the equilibrium Pliocene-preindustrial difference in Fig. 8b of this study. The transient RCP8.5 GPI difference in Camargo (2013) suggests a global increase (except for a small area in the central South Pacific where a decrease is expected). Meanwhile the equilibrium Pliocene-preindustrial difference in this study shows a general decrease (except for a region of the central North Pacific that has an increase in GPI). The stark difference in GPI response between the RCP8.5 and Pliocene therefore raises additional questions regarding the suitability of the choice of the Pliocene as a projection of modern-day greenhouse climate (Haywood et al., 2009), at least in terms of cyclogenesis-related measures. Held and Zhou (2011) show that TCs respond differently to the direct $\mathrm{CO}_{2}$ forcing and the resultant temperature changes. This may mean that the equilibrium climates simulated by PMIP should not be compared to the transient states driven by the future scenarios.

Emanuel (2013) downscaled six CMIP5 GCMs for the RCP8.5 projection and concluded that an increase in future global tropical cyclone activity might be expected. The same paper also acknowledged that other modelling groups obtained contrasting results where modest decreases (Knutson et al., 2010) and no robust change (Camargo, 2013) in future tropical cyclone activity had been detected. Emanuel (2013) and Camargo (2013) both supplemented their direct measures of cyclogenesis with an analysis of GPI that supports the directions of the changes found. Two models (CCSM4 and HasGEM2-ES) that Emanuel (2013) used for the RCP8.5 scenario are also incorporated into this study, but a decreasing trend is not detected for the two particular models here. Possible reasons that could account for the difference in- clude the use of a modified "clipped" vorticity GPI in this study, and a different choice of $250-850 \mathrm{hPa}$ tropospheric wind shear in Emanuel (2013). The striking difference in genesis potentials, despite a similar GCM choice, suggests that the GPI may be highly sensitive to slight adjustments in the diagnostic definition.

Kossin et al. (2014) showed that the lifetime maximum intensity of tropical cyclones is migrating polewards at a rate of about one degree of latitude per decade, similar to the rate of expansion of the tropics (Lucas et al., 2014). No coherent message about the poleward expansion of conditions favourable for cyclogenesis was found in this ensemble (not shown) and changes in GPI are found largely in the 10-20 region of both hemispheres, with minimum adjustment in the subtropics.

\section{Conclusions}

The cumulative global annual genesis potential index (a proxy for global tropical cyclone frequency) is found to have been relatively constant over the range of past climates. This range encompasses both warm (Pliocene) and cold (Last Glacial Maximum) climates and changing orbital forcing. These conditions are thought to represent the extremes of climates Earth has experienced in the past 3 million years. Often the members of the multi-model ensemble do not agree on the sign of the global change (Fig. 9), leading to high uncertainty in this headline metric.

The ensemble shows much higher levels of consistency on the regional scale, however. All five models agree on less potential for cyclogenesis in the North Atlantic at the Last Glacial Maximum. This is compensated for by an increased potential for cyclogenesis in the central North Pacific, to a greater or lesser degree. This is a circulation response to the existence of a large ice sheet over North America. A qualitatively similar feature has been seen previously (Korty et al., 2012a) but with some dependency on the ice sheet imposed (Abe-Ouchi et al., 2015). Obviously the reverse of such a pattern would not be expected in future. The mid-Holocene ensemble shows alterations of GPI associated with shifts in the intertropical convergence zone driven by the altered incoming solar distribution. Again the results from this ensemble are qualitatively similar to those from prior model ensembles (Korty et al., 2012b).

One motivation for studying past climate tropical cyclone response was to investigate its relationship to projections of the future. The genesis potential under the RCP8.5 scenario was computed and contrasted with the palaeoclimate response. There is no simple relationship that emerges between cumulative GPI and global temperature. This result implies that changes in the global frequency of tropical cyclones remain much less robust than regional responses. The conclusion is further strengthened by the apparent sensitivity of projected future global changes to the precise genesis 
potential index used - with our analysis not fully supporting either the results of Emanuel (2013) or the opposing results of Camargo (2013), despite all three using the same simulations.

Acknowledgements. The work was made possible through a scholarship awarded to J. H. Koh from the Ministry of the Environment and Water Resources, Singapore. The authors thank Suzana Camargo for her useful comments on GPI metrics and Kerry Emanuel for his assistance, not least his release of the potential intensity matlab routine. The assistance of Fran Bragg, Camille Contoux, Wing-Le Chan and Weipeng Zheng was essential to procure the necessary Pliocene simulation files. The creation of monthly climatologies for the PMIP3 simulations by Jean-Yves Peterschmitt was particularly helpful. The reviewer comments from Rob Korty, Matt Huber and Tim Merlis were very useful in clarifying the scope and presentation of this contribution.

Edited by: G. Lohmann

\section{References}

Abe-Ouchi, A., Saito, F., Kageyama, M., Braconnot, P., Harrison, S. P., Lambeck, K., Otto-Bliesner, B. L., Peltier, W. R., Tarasov, L., Peterschmitt, J.-Y., and Takahashi, K.: Ice-sheet configuration in the CMIP5/PMIP3 Last Glacial Maximum experiments, Geosci. Model Dev. Discuss., 8, 4293-4336, doi:10.5194/gmdd-8-42932015, 2015.

Annan, J. D. and Hargreaves, J. C.: A new global reconstruction of temperature changes at the Last Glacial Maximum, Clim. Past, 9, 367-376, doi:10.5194/cp-9-367-2013, 2013.

Ballinger, A. P., Merlis, T. M., Held, I. M., and Zhao, M.: The Sensitivity of Tropical Cyclone Activity to Off-Equatorial Thermal Forcing in Aquaplanet Simulations, J. Atmos. Sci., 72, 22862302, 2015.

Bister, M. and Emanuel, K. A.: Dissipative heating and hurricane intensity, Meteorol. Atmos. Phys., 65, 233-240, 1998.

Bister, M. and Emanuel, K. A.: Low frequency variability of tropical cyclone potential intensity 1 . Interannual to interdecadal variability, J. Geophys. Res.-Atmos. (1984-2012), 107, ACL 26-1ACL 26-15, 2002.

Bolton, D., The computation of equivalent potential temperature, Month. Weather Rev., 108, 1046-1053, 1980.

Braconnot, P., Otto-Bliesner, B., Harrison, S., Joussaume, S., Peterchmitt, J.-Y., Abe-Ouchi, A., Crucifix, M., Driesschaert, E., Fichefet, Th., Hewitt, C. D., Kageyama, M., Kitoh, A., Laîné, A., Loutre, M.-F., Marti, O., Merkel, U., Ramstein, G., Valdes, P., Weber, S. L., Yu, Y., and Zhao, Y.: Results of PMIP2 coupled simulations of the Mid-Holocene and Last Glacial Maximum Part 1: experiments and large-scale features, Clim. Past, 3, 261277, doi:10.5194/cp-3-261-2007, 2007.

Braconnot, P., Luan, Y., Brewer, S., and Zheng, W.: Impact of Earth's orbit and freshwater fluxes on Holocene climate mean seasonal cycle and ENSO characteristics, Clim. Dynam., 38, 1081-1092, 2012.

Bruyère, C. L., Holland, G. J., and Towler, E.: Investigating the Use of a Genesis Potential Index for Tropical Cyclones in the North Atlantic Basin, J. Clim., 25, 2012.
Camargo, S. J.: Global and Regional Aspects of Tropical Cyclone Activity in the CMIP5 Models, J. Climate, 26, 9880-9902, 2013.

Camargo, S. J., Sobel, A. H., Barnston, A. G., and Emanuel, K. A.: Tropical cyclone genesis potential index in climate models, Tellus A, 59, 428-443, 2007.

Camargo, S. J., Ting, M., and Kushnir, Y.: Influence of local and remote SST on North Atlantic tropical cyclone potential intensity, Clim. Dynam., 40, 1515-1529, 2013.

Camargo, S. J., Tippett, M. K., Sobel, A. H., Vecchi, G. A., and Zhao, M.: Testing the Performance of Tropical Cyclone Genesis Indices in Future Climates Using the HiRAM Model, J. Climate, 27, 9171-9196, 2014.

Chan, W.-L., Abe-Ouchi, A., and Ohgaito, R.: Simulating the midPliocene climate with the MIROC general circulation model: experimental design and initial results, Geosci. Model Dev., 4, 1035-1049, doi:10.5194/gmd-4-1035-2011, 2011.

Collins, M., Knutti, R., Arblaster, J. M., Dufresne, J.-L., Fichefet, T., Friedlingstein, P., Gao, X., Gutowski, W. J., Johns, T. C., Krinner, G., Shongwe, M., Tebaldi, C., Weaver, A. J., and Wehner, M. F.: Long-term Climate Change: Projections, Commitments and Irreversibility, in: Climate Change 2013: The Physical Science Basis, edited by: Stocker, T. F., Dahe, Q., Plattner, G.-K., Tignor, M., Allen, S. K., Boschung, J., Nauels, A., Xia, Y., Bex, V., and Midgley, P. M., Cambridge University Press, Cambridge, United Kingdom and New York, NY, USA, 1029-1136, 2013.

Collins, W. J., Bellouin, N., Doutriaux-Boucher, M., Gedney, N., Halloran, P., Hinton, T., Hughes, J., Jones, C. D., Joshi, M., Liddicoat, S., Martin, G., O’Connor, F., Rae, J., Senior, C., Sitch, S., Totterdell, I., Wiltshire, A., and Woodward, S.: Development and evaluation of an Earth-System model - HadGEM2, Geosci. Model Dev., 4, 1051-1075, doi:10.5194/gmd-4-10512011, 2011.

Contoux, C., Ramstein, G., and Jost, A.: Modelling the midPliocene Warm Period climate with the IPSL coupled model and its atmospheric component LMDZ5A, Geosci. Model Dev., 5, 903-917, doi:10.5194/gmd-5-903-2012, 2012.

DiNezio, P. N. and Tierney, J. E.: The effect of sea level on glacial Indo-Pacific climate, Nature Geosci., 6, 485-491, 2013.

DiNezio, P. N., Clement, A. C., Vecchi, G. A., Soden, B. J., Broccoli, A. J., Otto-Bliesner, B. L., and Braconnot, P.: The response of the Walker circulation to Last Glacial Maximum forcing: Implications for detection in proxies, Paleoceanography, 26 , PA3217, doi:10.1029/2010PA002083, 2011.

Dowsett, H. J., Robinson, M. M., Stoll, D. K., and Foley, K. M.: Mid-Piacenzian mean annual sea surface temperature analysis for data-model comparisons, Stratigraphy, 7, 189-198, 2010.

Dufresne, J. L., Foujols, M. A., Denvil, S., Caubel, A., Marti, O., Aumont, O., Balkanski, Y., Bekki, S., Bellenger, H., Benshila, R., Bony, S., Bopp, L., Braconnot, P., Brockmann, P., Cadule, P., Cheruy, F., Codron, F., Cozic, A., Cugnet, D., de Noblet, N., Duvel, J. P., Ethé, C., Fairhead, L., Fichefet, T., Flavoni, S., Friedlingstein, P., Grandpeix, J. Y., Guez, L., Guilyardi, E., Hauglustaine, D., Hourdin, F., Idelkadi, A., Ghattas, J., Joussaume, S., Kageyama, M., Krinner, G., Labetoulle, S., Lahellec, A., Lefebvre, M. P., Lefevre, F., Levy, C., Li, Z. X., Lloyd, J., Lott, F., Madec, G., Mancip, M., Marchand, M., Masson, S., Meurdesoif, Y., Mignot, J., Musat, I., Parouty, S., Polcher, J., Rio, C., Schulz, M., Swingedouw, D., Szopa, S., Talandier, C., Terray, 
P., Viovy, N., and Vuichard, N.: Climate change projections using the IPSL-CM5 Earth System Model: from CMIP3 to CMIP5, Clim. Dynam., 40, 2123-2165, 2013.

Dunkerton, T. J., Montgomery, M. T., and Wang, Z.: Tropical cyclogenesis in a tropical wave critical layer: easterly waves, Atmos. Chem. Phys., 9, 5587-5646, doi:10.5194/acp-9-5587-2009, 2009.

Emanuel, K. A.: The maximum intensity of hurricanes, J. Atmos. Sci., 45, 1143-1155, 1988.

Emanuel, K. A.: The theory of hurricanes, Ann. Rev. Fluid Mechan., 23, 179-196, 1991.

Emanuel, K. A.: Atmospheric convection: Oxford University Press, 1994.

Emanuel, K. A.: Sensitivity of Tropical Cyclones to Surface Exchange Coefficients and a Revised Steady-State Model incorporating Eye Dynamics, J. Atmos. Sci., 52, 3969-3976, 1995a.

Emanuel, K. A.: The behavior of a simple hurricane model using a convective scheme based on subcloud-layer entropy equilibrium, J. Atmos. Sci., 52, 3960-3968, 1995b.

Emanuel, K. A.: Tropical cyclones, Ann. Rev. Earth Planet. Sci., 31, 75-104, 2003.

Emanuel, K. A.: Downscaling CMIP5 climate models shows increased tropical cyclone activity over the 21 st century, Proc. Natl. Acad. Sci., 110, 12219-12224, 2013.

Emanuel, K. A. and Nolan, D. S.: Tropical cyclone activity and the global climate system, 2004.

Emanuel, K., Sundararajan, R., and Williams, J.: Hurricanes and Global Warming: Results from Downscaling IPCC AR4 Simulations, Bull. Am. Meteorol. Soc., 89, 347-367, 2008.

Fedorov, A. V., Brierley, C. M., and Emanuel, K.: Tropical cyclones and permanent El Niño in the early Pliocene epoch, Nature, 463, 1066-1070, 2010.

Fedorov, A. V., Brierley, C. M., Lawrence, K. T., Liu, Z., Dekens, P. S., and Ravelo, A. C.: Patterns and mechanisms of early Pliocene warmth, Nature, 496, 43-49, 2013.

Frank, W. M. and Ritchie, E. A.: Effects of Vertical Wind Shear on the Intensity and Structure of Numerically Simulated Hurricanes, Month. Weather Rev., 129, 2249-2269, 2001.

Gagan, M. K., Ayliffe, L. K., Hopley, D., Cali, J. A., Mortimer, G. E., Chappell, J., McCulloch, M. T., and Head, M. J.: Temperature and surface-ocean water balance of the mid-Holocene tropical western Pacific, Science, 279, 1014-1018, 1998.

Garner, S.: The relationship between Hurricane Potential Intensity and CAPE, J. Atmos. Sci., 72, 141-163, 2015.

Gent, P. R., Danabasoglu G., Donner, L. J., Holland, M. M., Hunke, E. C., Jayne, S. R., Lawrence, D. M., Neale, R. B., Rasch, P. J., and Vertenstein, M.: The Community Climate System Model Version 4, J. Climate, 24, 4973-4991, doi:10.1175/2011JCLI4083.1, 2011.

Gordon, C., Cooper, C., Senior, C. A., Banks, H., Gregory, J. M., Johns, T. C., Mitchell, J. F. B., and Wood, R. A.: The simulation of SST, sea ice extents and ocean heat transports in a version of the Hadley Centre coupled model without flux adjustments, Clim. Dynam., 16, 147-168, 2000.

Gray, W. M.: Global view of the origin of tropical disturbances and storms, Month. Weather Rev., 96, 669-700, 1968.

Gray, W. M.: Tropical Cyclone Genesis in the Western North Pacific, DTIC Document, 1975.
Haywood, A. M., Dowsett, H. J., Valdes, P. J., Lunt, D. J., Francis, J. E., and Sellwood, B. W.: Introduction, Pliocene climate, processes and problems, Philosoph. Trans. Roy. Soc. A, 367, 3-17, 2009.

Haywood, A. M., Dowsett, H. J., Robinson, M. M., Stoll, D. K., Dolan, A. M., Lunt, D. J., Otto-Bliesner, B., and Chandler, M. A.: Pliocene Model Intercomparison Project (PlioMIP): experimental design and boundary conditions (Experiment 2), Geosci. Model Dev., 4, 571-577, doi:10.5194/gmd-4-571-2011, 2011.

Hill, D. J., Haywood, A. M., Lunt, D. J., Hunter, S. J., Bragg, F. J., Contoux, C., Stepanek, C., Sohl, L., Rosenbloom, N. A., Chan, W.-L., Kamae, Y., Zhang, Z., Abe-Ouchi, A., Chandler, M. A., Jost, A., Lohmann, G., Otto-Bliesner, B. L., Ramstein, G., and Ueda, H.: Evaluating the dominant components of warming in Pliocene climate simulations, Clim. Past, 10, 79-90, doi:10.5194/cp-10-79-2014, 2014.

Holland, G. J.: The maximum potential intensity of tropical cyclones, J. Atmos. Sci., 54, 2519-2541, 1997.

Jourdain, N. C., Marchesiello, P., Menkes, C. E., Lefèvre, J., Vincent, E. M., Lengaigne, M., and Chauvin, F.: Mesoscale Simulation of Tropical Cyclones in the South Pacific: Climatology and Interannual Variability, J. Climate, 24, 3-25, 2010.

Kamae, Y., Ueda, H., and Kitoh, A.: Hadley and Walker Circulations in the Mid-Pliocene Warm Period Simulated by an Atmospheric General Circulation Model, J. Meteorol. Soc. Japan. Ser. II, 89, 475-493, 2011.

Klotzbach, P. J.: Trends in global tropical cyclone activity over the past twenty years (1986-2005), Geophys. Res. Lett., 33, L10805, doi:10.1029/2006GL025881, 2006.

Knapp, K. R., Kruk, M. C., Levinson, D. H., Diamond, H. J., and Neumann, C. J.: The International Best Track Archive for Climate Stewardship (IBTrACS), Dx. Doi. Org, 91, 363-376, 2010.

Knutson, T. R., McBride, J. L., Chan, J., Emanuel, K., Holland, G., Landsea, C., Held, I., Kossin, J. P., Srivastava, A. K., and Sugi, M.: Tropical cyclones and climate change, Nature Geosci., 3, 157-163, 2010.

Knutson, T. R., Sirutis, J. J., Vecchi, G. A., Garner, S., Zhao, M., Kim, H.-S., Bender, M., Tuleya, R. E., Held, I. M., and Villarini, G.: Dynamical Downscaling Projections of Twenty-FirstCentury Atlantic Hurricane Activity: CMIP3 and CMIP5 ModelBased Scenarios, J. Clim., 26, 6591-6617, doi:10.1175/JCLI-D12-00539.1, 2013.

Korty, R. L., Camargo, S. J., and Galewsky, J.: Tropical Cyclone Genesis Factors in Simulations of the Last Glacial Maximum, J. Climate, 25, 4348-4365, doi:10.1175/JCLI-D-11-00517.1, 2012a.

Korty, R. L., Camargo, S. J., and Galewsky, J.: Variations in Tropical Cyclone Genesis Factors in Simulations of the Holocene Epoch, J. Climate, 25, 8196-8211, doi:10.1175/jcli-d12-00033.1, 2012b.

Kossin, J. P., Emanuel, K. A., and Vecchi, G. A.: The poleward migration of the location of tropical cyclone maximum intensity, Nature, 509, 349-352, 2014.

Koutavas, A., Lynch-Stieglitz, J., Marchitto, T. M., and Sachs, J. P.: El Nino-like pattern in ice age tropical Pacific sea surface temperature, Science, 297, 226-230, 2002.

Kuhnert, H., Kuhlmann, H., Mohtadi, M., Meggers, H., Baumann, K.-H., and Pätzold, J.: Holocene tropical Western Indian Ocean sea surface temperatures in covariation with climatic 
changes in the Indonesian region, Paleoceanography, 29, 423437, doi:10.1002/2013PA002555, 2014.

Lewis, S. and Maslin, M.: Defining the Anthropocene, Nature, 519, 171-180 2014.

Li, L., Lin, P., Yu, Y., Wang, B., Zhou, T., Liu, L., Liu, J., Bao, Q., Xu, S., Huang, W., Xia, K., Pu, Y., Dong, L., Shen, S., Liu, Y., Hu, N., Liu, M., Sun, W., Shi, X., Zheng, W., Wu, B., Song, M., Liu, H., Zhang, X., Wu, G., Xue, W., Huang, X., Yang, G., Song, Z., and Qiao, F.: The flexible global ocean-atmosphereland system model, Grid-point Version 2: FGOALS-g2, Adv. Atmos. Sci., 30, 543-560, 2013.

Luan, Y., Braconnot, P., Yu, Y., Zheng, W., and Marti, O.: Early and mid-Holocene climate in the tropical Pacific: seasonal cycle and interannual variability induced by insolation changes, Clim. Past, 8, 1093-1108, doi:10.5194/cp-8-1093-2012, 2012.

Lucas, C., Timbal, B., and Nguyen, H.: The expanding tropics: a critical assessment of the observational and modeling studies, Wiley Interdisciplinary Reviews, Clim. Change, 5, 89-112, 2014.

Menkes, C. E., Lengaigne, M., Marchesiello, P., Jourdain, N. C., Vincent, E. M., Lefèvre, J., Chauvin, F., and Royer, J.-F.: Comparison of tropical cyclogenesis indices on seasonal to interannual timescales, Clim. Dynam., 38, 301-321, 2012.

Merlis, T. M., Zhao, M., and Held, I. M.: The sensitivity of hurricane frequency to ITCZ changes and radiatively forced warming in aquaplanet simulations, Geophys. Res. Lett., 40, 4109-4114, 2013.

Montgomery, M. T., Smith, R. K., and Nguyen, S. V.: Sensitivity of tropical-cyclone models to the surface drag coefficient, Quarterly J. Roy. Meteorol. Soc., 136, 1945-1953, 2010.

Nolan, D. S. and Rappin, E. D.: Increased sensitivity of tropical cyclogenesis to wind shear in higher SST environments, Geophys. Res. Lett., 35, L14805, doi:10.1029/2008GL034147, 2008.

O’Brien, C., Foster, G., Martínez-Botí, M., Abell, R., Rae, J., and Pancost, R.: High sea surface temperatures in tropical warm pools during the Pliocene, Nature Geosci., 7, 606-611, 2014.

Pagani, M., Liu, Z., LaRiviere, J., and Ravelo, A. C.: High Earthsystem climate sensitivity determined from Pliocene carbon dioxide concentrations, Nature Geosci., 3, 27-30, 2009.

Ravelo, A. C., Lawrence, K. T., Fedorov, A., and Ford, H. L.: Comment on "A 12-million-year temperature history of the tropical Pacific Ocean”, Science, 346, 1467-1467, 2014.

Riemer, M., Montgomery, M. T., and Nicholls, M. E.: Further examination of the thermodynamic modification of the inflow layer of tropical cyclones by vertical wind shear, Atmos. Chem. Phys., 13, 327-346, doi:10.5194/acp-13-327-2013, 2013.

Rimbu, N., Lohmann, G., Lorenz, S. J., Kim, J. H., and Schneider, R. R.: Holocene climate variability as derived from alkenone sea surface temperature and coupled ocean-atmosphere model experiments, Clim. Dynam., 23, 215-227, 2004.

Saint-Lu, M., Braconnot, P., Leloup, J., Lengaigne, M., and Marti, O.: Changes in the ENSO/SPCZ relationship from past to future climates, Earth Planet. Sci. Lett., 412, 18-24, 2015.
Stott, L., Cannariato, K., Thunell, R., Haug, G. H., Koutavas, A., and Lund, S.: Decline of surface temperature and salinity in the western tropical Pacific Ocean in the Holocene epoch, Nature, 431, 56-59, 2004.

Sueyoshi, T., Ohgaito, R., Yamamoto, A., Chikamoto, M. O., Hajima, T., Okajima, H., Yoshimori, M., Abe, M., O'ishi, R., Saito, F., Watanabe, S., Kawamiya, M., and Abe-Ouchi, A.: Set-up of the PMIP3 paleoclimate experiments conducted using an Earth system model, MIROC-ESM, Geosci. Model Dev., 6, 819-836, doi:10.5194/gmd-6-819-2013, 2013.

Tippett, M. K., Camargo, S. J., and Sobel, A. H.: A Poisson Regression Index for Tropical Cyclone Genesis and the Role of LargeScale Vorticity in Genesis, J. Climate, 24, 2335-2357, 2010.

Tory, K. J., Dare, R. A., Davidson, N. E., McBride, J. L., and Chand, S. S.: The importance of low-deformation vorticity in tropical cyclone formation, Atmos. Chem. Phys., 13, 2115-2132, doi:10.5194/acp-13-2115-2013, 2013.

Vecchi, G. A., Swanson, K. L., and Soden, B. J.: Whither hurricane activity, Science, 322, 687, doi:10.1126/science.1164396, 2008.

Velden, C. S. and Sears, J.: Computing Deep-Tropospheric Vertical Wind Shear Analyses for Tropical Cyclone Applications: Does the Methodology Matter?, Weather Forecast., 29, 1169-1180, doi:10.1175/WAF-D-13-00147.1, 2014.

Villarini, G., and Vecchi, G.: North Atlantic Power Dissipation Index (PDI) and Accumulated Cyclone Energy (ACE): Statistical Modeling and Sensitivity to Sea Surface Temperature Changes, J. Climate, 25, 625-637, 2012.

Waelbroeck, C., Paul, A., Kucera, M., Rosell-Melé, A., Weinelt, M., Schneider, R., Mix, A. C., Abelmann, A., Armand, L., Bard, E., Barker, S., Barrows, T. T., Benway, H., Cacho, I., Chen, M. T., Cortijo, E., Crosta, X., de Vernal, A., Dokken, T., Duprat, J., Elderfield, H., Eynaud, F., Gersonde, R., Hayes, A., Henry, M., Hillaire-Marcel, C., Huang, C. C., Jansen, E., Juggins, S., Kallel, N., Kiefer, T., Kienast, M., Labeyrie, L., Leclaire, H., Londeix, L., Mangin, S., Matthiessen, J., Marret, F., Meland, M., Morey, A. E., Mulitza, S., Pflaumann, U., Pisias, N. G., Radi, T., Rochon, A., Rohling, E. J., Sbaffi, L., Schäfer-Neth, C., Solignac, S., Spero, H., Tachikawa, K., Turon, J.: Constraints on the magnitude and patterns of ocean cooling at the Last Glacial Maximum, Nat. Geosci., 2, doi:10.1038/ngeo411, 127-132, 2009.

Webster, P. J., Holland, G. J., Curry, J. A., and Chang, H. R.: Changes in tropical cyclone number, duration, and intensity in a warming environment, Science, 309, 1844-1846, 2005.

Zhang, Y. G., Pagani, M., and Liu, Z.: A 12-million-year temperature history of the tropical Pacific Ocean, Science, 344, 84-87, 2014a.

Zhang, Y. G., Pagani, M., and Liu, Z.: Response to Comment on "A 12-million-year temperature history of the tropical Pacific Ocean" Science, 346, 1467-1467, 2014b. 